\title{
FATORES ASSOCIADOS AO SOBREPESO E OBESIDADE DE INDIVÍDUOS DE 8 A 18 ANOS DE IDADE
}

\author{
MARIA FERNANDA PETROLI FRUTUOSO
}

Tese apresentada ao Departamento de Nutrição da Faculdade de Saúde Pública da Universidade de São Paulo, para obtenção do título de Doutor em Saúde Pública.

Área de concentração: Nutrição

Orientadora: Profa Dra. Ana Maria Gambardella

São Paulo

2003 
À Ana Carolina, amiga e parceira de todas as horas 
Autorizo, exclusivamente para fins acadêmicos e científicos, a reprodução total ou parcial desta tese, por processos fotocopiadores.

Assinatura:

Data: 


\section{AGRADECIMENTOS}

A todas as crianças e adolescentes e a seus pais e/ou familiares que participaram desta pesquisa.

Aos diretores, coordenadores, inspetores de alunos, professores e funcionários das escolas que colaboraram e tornaram possivel a realização deste estudo.

À Ana Maria Gambardella pelo incentivo na realização da pós-graduação.

Aos Professores José Maria Pacheco de Souza e Maria de Fátima Nunes Marucci pelas sugestões e comentários sobre a tese.

Aos meus pais, Oscar e Sônia, pelo apoio e investimento em minha formação. Ao meu irmão Rodrigo e às primas-irmãs Claudia Giorio e Edna Giorio.

Ao amigo Wolney Conde pelo convivio durante a pós-graduação.

À Sueli Keiko Takasu, Bianca Iuliano, Elizabeth Bismarck-Nasr e Claudia Franchi pela amizade incondicional. Ao amigo Alex Florindo pela ajuda com a tese.

A Guilherme Montes Naked pelos cafés e conversas...

Aos funcionários do departamento de nutrição, especialmente à Alessandra Blaya Frutuoso por tornar os fins de tarde mais divertidos.

Às colegas Neusa Moura e Eliza Murakoshi pela ajuda com os inquéritos alimentares. A Luiz Gustavo Camargo pelas manhãs divertidas e agradáveis.

Ao Conselho Nacional de Desenvolvimento Cientifico e Tecnológico - CNPq pela bolsa de estudo concedida. 
Gracias a la vida que me ha dado tanto: Me ha dado la riza y me ha dado el llanto; Así yo distingo dicha de quebranto Los dos materiales que forman mi canto, Gracias a la vida que me ha dado tanto. 
The fatter of the fattest appear to be getting fatter fastest

W. Dietz 
RESUMO 


\section{RESUMO}

\section{FRUTUOSO MFP. Fatores associados ao sobrepeso e obesidade de}

individuos de 8 a 18 anos de idade. São Paulo; 2003. [Tese de Doutorado Faculdade de Saúde Pública da Universidade de São Paulo]

Introdução: A adolescência é considerada um importante período do desenvolvimento do individuo, uma vez que mudanças fisiológicas ocorridas nesta fase têm repercussões na saúde atual e futura dos adolescentes. Estudos epidemiológicos apontam aumento da prevalência de sobrepeso e obesidade infanto-juvenil no mundo todo, inclusive no Brasil, com conseqüências importantes a curto e a longo prazo, incluindo aumento da pressão arterial, colesterol total e glicose sangüínea, bem como dificuldade de socialização e interação, imagem corporal distorcida e baixa auto-estima, entre outras. Objetivo: O presente estudo teve como objetivo analisar os fatores associados ao sobrepeso e obesidade em indivíduos de 8 a 18 anos de idade. Metodologia: Foram realizadas análises de regressão linear múltipla, utilizando, como variáveis dependentes, os dados transversais (da primeira coleta) e longitudinais (diferença entre a terceira e primeira coletas) do índice de massa corporal (IMC) e gordura corporal ( $\mathrm{kg}$ e \%, obtida por impedância bioelétrica). As variáveis independentes foram consumo de lipídios e valor energético da dieta (recordatório de 24 horas), atividade física e sedentarismo (questionário), idade, estágio de maturação sexual (auto referido), sexo, peso ao nascer, IMC e escolaridade materna e renda per capita. Foi realizada regressão logística, utilizando como variável dependente a presença/ausência de sobrepeso/obesidade baseada nos valores de IMC/idade/sexo propostos por COLE e col. (2000). Resultados: Foram estudados 483 individuos no seguimento. Para ambos os sexos, analisando os dados transversais, as variáveis significativas para todas as variáveis dependentes foram idade, IMC materno e renda per capita. O peso ao nascer associou-se somente para o sexo feminino. Na análise longitudinal, entre as meninas, a principal variável associada foi o valor inicial. Para os meninos, as variáveis associadas foram 
valor inicial, idade e renda per capita. Foi encontrada prevalência de sobrepeso de 26,3 e $28,7 \%$ e de obesidade de 7,3 e 12,6\%, para meninas e meninos, respectivamente. Observou-se que as variáveis obesidade materna e peso ao nascer acima de $3500 \mathrm{~g}$ foram fatores de risco para a presença de sobrepeso. Para obesidade, obesidade materna foi a principal preditora. Conclusões: Conclui-se que individuos de 8 a 18 anos de idade, filhos de mães obesas, estão 4,2 vezes mais propensos à obesidade e têm chance 2 vezes maior de apresentarem sobrepeso em relação aos filhos de mães eutróficas. Sexo e os valores iniciais das variáveis dependentes constituem as principais variáveis associadas às variações temporais de IMC e massa adiposa em crianças e adolescentes, enquanto sexo, idade, renda per capita e IMC materno estão associadas aos valores transversais.

Descritores: adolescência, sobrepeso, obesidade, fatores de risco, estudo longitudinal. 
SUMMARY 


\section{SUMMARY}

FRUTUOSO MFP. Fatores associados ao sobrepeso e obesidade de individuos de 8 a 18 anos de idade. [Factors associated to overweight and obesity among subjects aged 8 to 18 years] São Paulo (BR); 2000. [Tese de Doutorado - Faculdade de Saúde Pública da Universidade de São Paulo].

Introduction: Adolescence is considered an important period in the human growth once physiological changes take place and affect the present and future adolescent health. Epidemiological studies show a rapidly increasing in the child-adolescent obesity prevalence worldwide, including Brazil. Obesity has many health consequences in short and long-term, such as raised blood pressure, total cholesterol and glucose level. Effects in psychological heath are impaired social interaction, body image dissatisfaction and low self esteem. Objective: The present study aimed to analyze the factors associated to overweight and obesity among subjects aged 8 to 18 years. Methodology: Multiple regression analysis were performed using the cross-sectional data (outcome variable: value at baseline) and cohort data (outcome variable: difference between follow-up and baseline measures) for body mass index (BMI) and body fat ( $\mathrm{kg}$ and \% by bioelectrical impedance). The independent variables were energy and fat intake (24 hours recall), physical activity and inactivity (questionnaire), age, sexual maturation (self-reported), gender, birth weight, mothers' BMI, per capita income and mothers' schooling. The overweight/obesity prevalence was assessed through BMl/age/gender proposed by COLE e col. (2000) and it was analyzed by logistic regression. Results: Forty-hundred eighteen three children and teenagers were studied. For males and females, age, parents' BMI and per capita income were associated with the cross-sectional variables. Birth weight was related to BMI and body fatness $(\mathrm{kg})$ only for girls. The major determinants of changes in BMI and body fat among girls were baseline values. The per capita income, age and baseline values were related to body composition changes among boys. The overweight prevalence was 26.3 e $28.7 \%$ and the obesity prevalence was $7.3 \mathrm{e}$ 
$12.6 \%$, for females and males, respectively. The main predictor of overweight and obesity was mother obesity. Birth weight up to $3500 \mathrm{~g}$ was risk factor for overweight. Conclusion: When the mother is obese, the adolescent obesity risk is 4.2 times greater and the adolescent overweight risk is twice compared to when the mother is no obese. The baseline values and gender were the main predictors of body composition changes and age, gender, per capita income and mothers' BMI were associated with the cross-sectional values.

Descriptors: adolescence, overweight, obesity, risk factors, cohort study. 


\section{ÍNDICE}

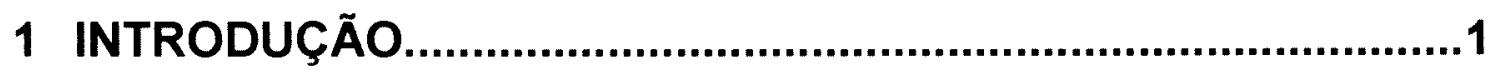

1.1 Puberdade: maturação sexual, antropometria e composição corporal.....2

1.2 Puberdade: desenvolvimento sexual e estado nutricional........................4

1.3 Sobrepeso e obesidade: conseqüências e prevalência............................ 6

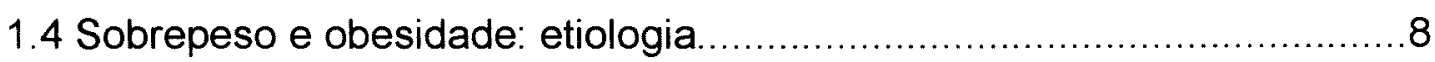

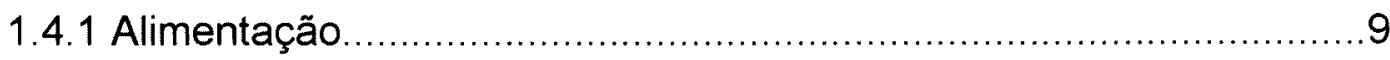

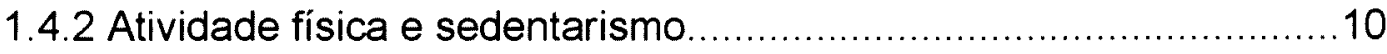

1.4.3 Nível Sócio-econômico (NSE) ..................................................12

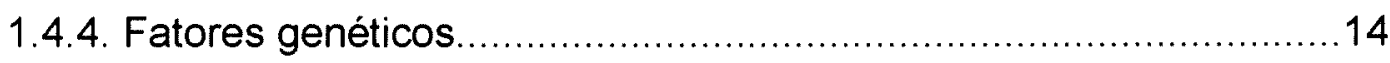

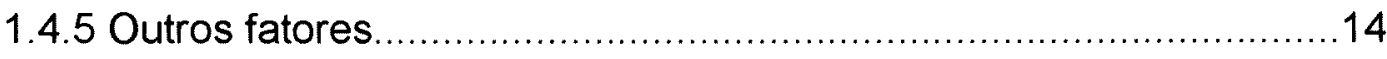

2 OBJETIVO GERAL...........................................................17

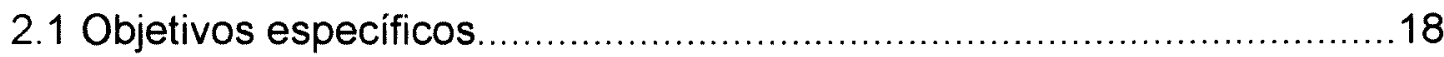

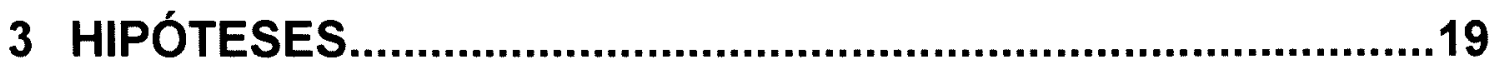

4 MATERIAL E MÉTODOS......................................................21

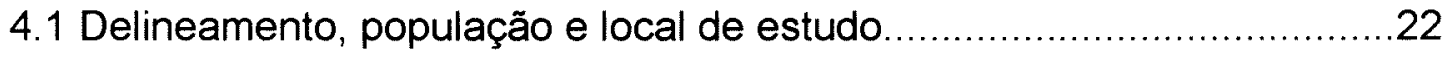

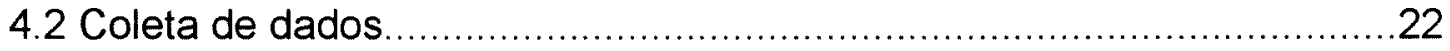

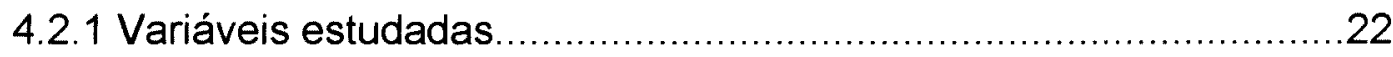

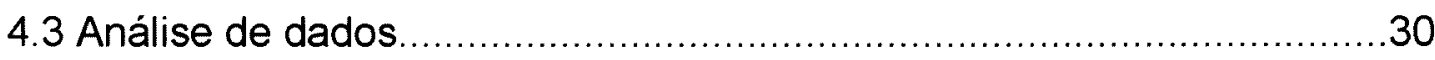

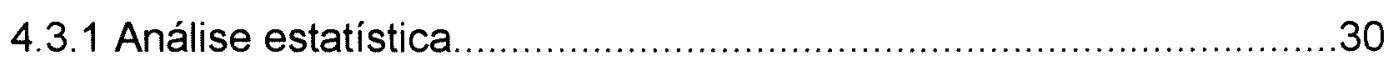

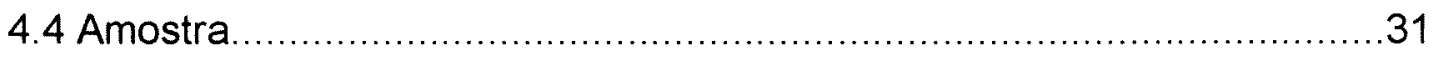

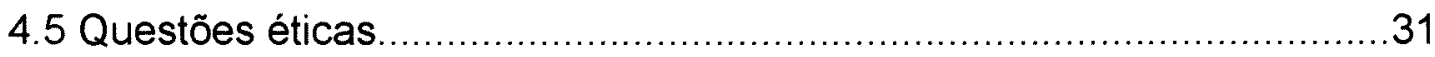

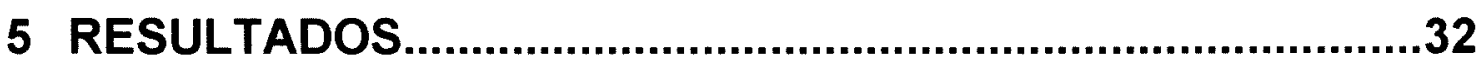

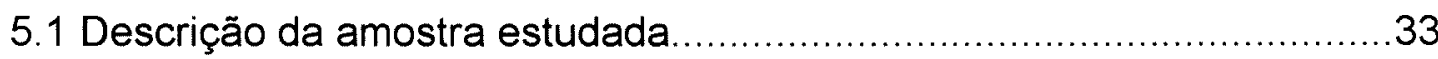

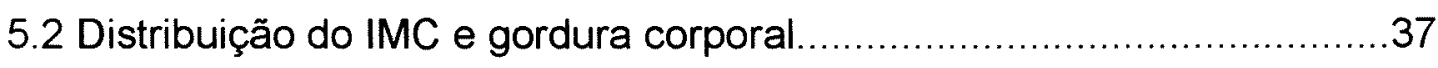

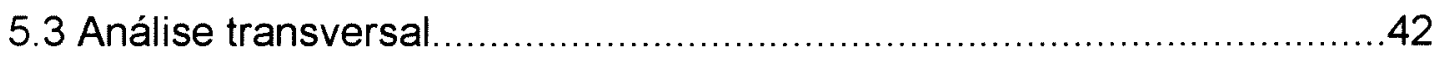

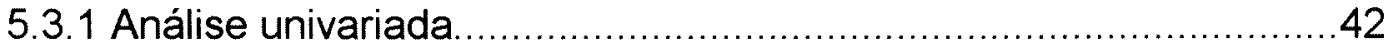




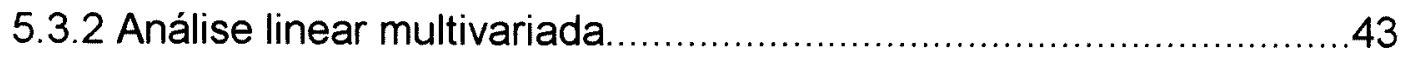

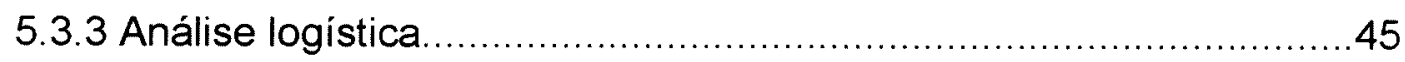

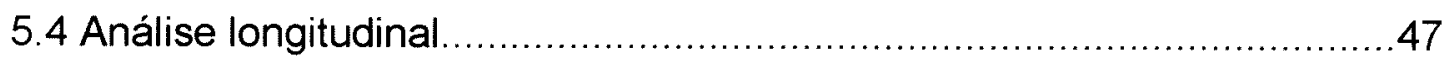

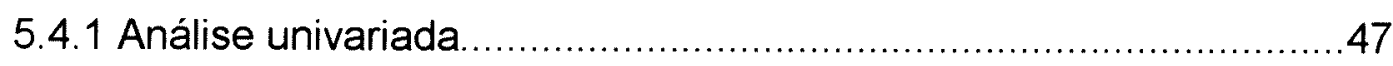

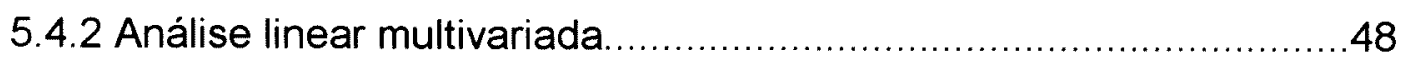

6 DISCUSSÃO.....................................................................50

6.1 Validade interna

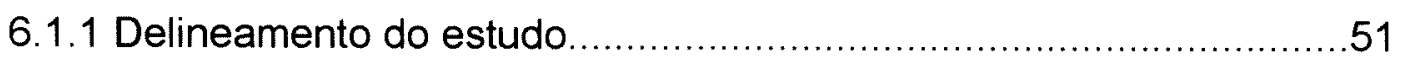

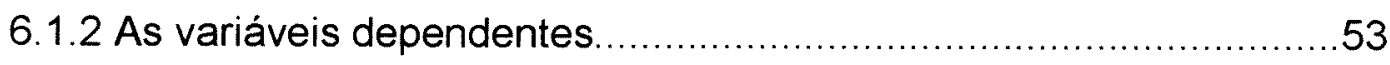

6.1.2.1 O IMC e o diagnóstico de sobrepeso/obesidade.....................53

6.1.2.2 BIA e a composição corporal..................................................54

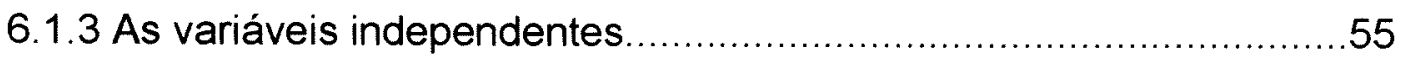

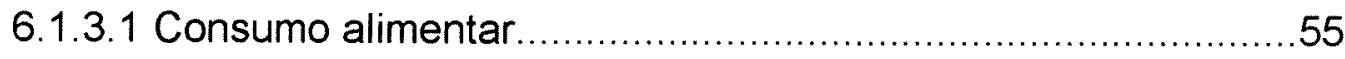

6.1.3.2 Atividade física e sedentarismo...........................................57

6.1.3.3 Idade e estágio de maturação sexual....................................59

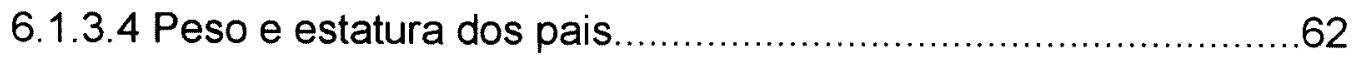

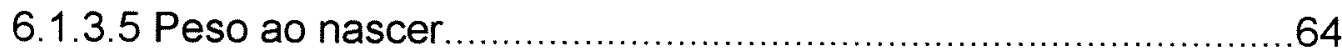

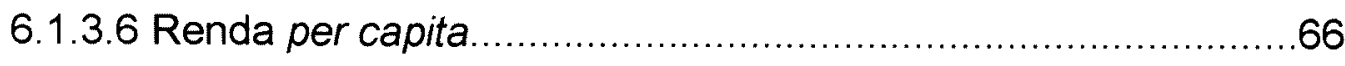

6.1.3.7 Valor inicial da variável dependente......................................68

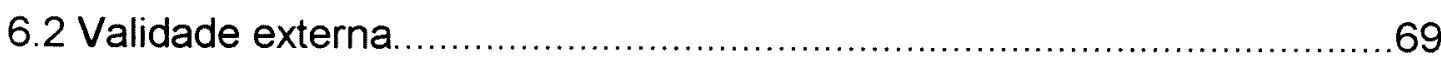

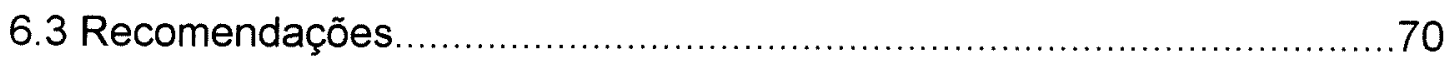

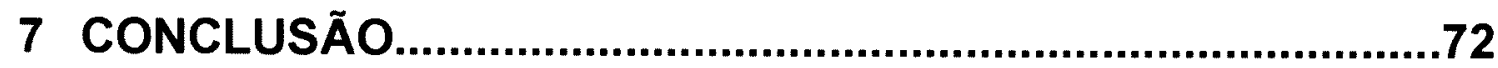

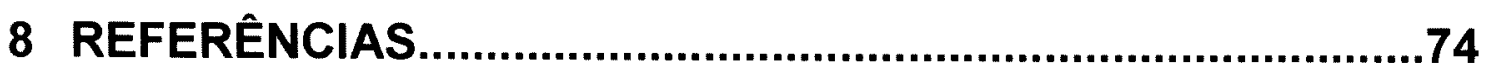

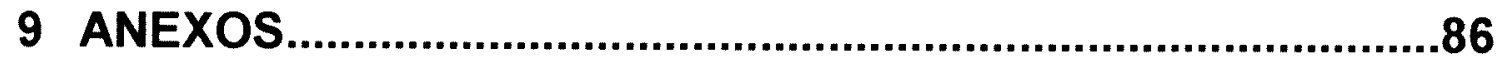




\section{ÍNDICE DE QUADROS, FIGURAS E TABELAS}

\section{Figuras:}

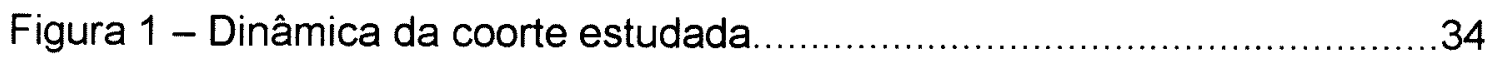

\section{Quadros:}

Quadro 1 - Características dos macronutrientes.

Quadro 2 - Variáveis que influenciam o peso corporal de crianças e adolescentes

Quadro 3 - Pontos de corte de IMC para sobrepeso e obesidade segundo sexo e idade.

\section{Tabelas:}

Tabela 1 - Distribuição das variáveis dependentes - média (desvio-padrão) segundo sexo e coleta realizada.

Tabela 2 - Distribuição das variáveis independentes - média (desvio-padrão) segundo sexo e coleta realizada.

Tabela 3 - Distribuição das variáveis dependentes - média (desvio-padrão) segundo variáveis independentes.

Tabela 4 - Distribuição da prevalência de sobrepeso e obesidade, segundo variáveis independentes. 40

Tabela 5 - Coeficientes de correlação entre as variáveis dependentes e independentes segundo sexo 
Tabela 6 - Análise linear multivariada para o sexo feminino $(n=290)$, segundo valor transversal das variáveis dependentes.

Tabela 7 - Análise linear multivariada para o sexo masculino $(n=163)$, segundo valor transversal das variáveis dependentes.

Tabela 8 - Preditores de sobrepeso nos individuos estudados. 46

Tabela 9 - Preditores de obesidade nos indivíduos estudados 46

Tabela 10 - Coeficientes de correlação entre as variáveis dependentes e independentes segundo sexo.

Tabela 11 - Análise linear multivariada para o sexo feminino, segundo variação temporal das variáveis dependentes .48

Tabela 12 - Análise linear multivariada para o sexo masculino, segundo variação temporal das variáveis dependentes. 49 
INTRODUÇÃO 


\section{INTRODUÇÃO}

\subsection{Puberdade: maturação sexual, antropometria e composição corporal}

$\mathrm{Na}$ adolescência, período compreendido entre 10 e 19 anos de idade, está inserida a puberdade, etapa de maturação biológica marcada pelo surgimento de caracteres sexuais secundários, estirão de crescimento e modificações da composição corporal. Durante a puberdade, ocorre a maior diferenciação sexual desde a vida fetal e a maior velocidade de crescimento linear desde a infância (WHO 1995).

As alterações no tamanho, forma e composição corporais, características da puberdade, ocorrem em diferentes idades em meninos e em meninas. No sexo feminino, é um fenômeno que caracteriza a primeira metade do período puberal, enquanto que no masculino ocorre na segunda metade do mesmo (ROGOL e col. 2002).

O desenvolvimento sexual apresenta uma seqüência definida para cada sexo, porém, variações temporais individuais ocorrem normalmente. A maturação sexual ocorre durante a puberdade por influência dos hormônios esteróides gonadais (predominantemente testosterona para meninos e estradiol para meninas) e, principalmente por hormônios andróginos adrenais (ROGOL e col. 2000).

Para os dois sexos, a produção destes hormônios resulta, inicialmente no aparecimento de pêlos pubianos, culminando com 0 total desenvolvimento sexual. $O$ início destas alterações antes dos 9 anos é considerado precoce e após os 14, tardio (ROGOL e col. 2002).

Durante a puberdade, observa-se crescimento e alterações rápidas e intensas com ganho de aproximadamente $20 \%$ da estatura e $50 \%$ do peso do indivíduo adulto. $O$ aumento de peso, bem como o da estatura, apresenta, na 
adolescência, uma fase de aceleração e posterior desaceleração e a velocidade máxima de ganho de peso pode coincidir ou ocorrer posteriormente ao pico de crescimento esquelético (ROGOL e col. 2000).

Um dos indicadores da puberdade é o estirão de crescimento. Quando a puberdade aproxima-se, a velocidade de crescimento decresce a um valor mais baixo, antes de uma repentina aceleração durante a puberdade. $O$ estirão de crescimento pubertal ocorre anteriormente nas meninas e não alcança a mesma magnitude quando comparado aos meninos. No sexo feminino, o pico de velocidade de crescimento é de $9 \mathrm{~cm} / a n o$ aos 12 anos de idade, em média, e ocorre um ganho total de estatura de $25 \mathrm{~cm}$ durante o período de crescimento pubertário (WHO 1995).

Meninos alcançam um pico de velocidade de crescimento de 10,3 cm/ano, em média, 2 anos mais tarde que as meninas e um ganho total de $28 \mathrm{~cm}$ em estatura. A maior duração do crescimento pré-puberal em combinação com o maior pico de velocidade de crescimento resultam em uma diferença média na estatura final adulta de $13 \mathrm{~cm}$ entre mulheres e homens (WHO 1995).

Após o pico de crescimento, segue-se gradual desaceleração de ganho estatural até a parada de crescimento ao redor de 15 ou 16 anos para o sexo feminino e de 17 ou 18 anos para o masculino (ROGOL e col. 2000).

$\mathrm{Na}$ adolescência, observam-se processos dinâmicos de crescimento e maturação física, englobando mudanças somáticas e celulares. A avaliação do crescimento, tradicionalmente, enfoca a estatura, embora alterações na composição corporal sejam elementos essenciais para o processo de crescimento (ROGOL e col. 2002).

Durante a puberdade, observa-se o crescimento fisiológico de todos os tecidos e as alterações na composição corporal, incluindo distribuição regional de gordura 
corporal, são intensas durante a transição puberal e marcadamente diferentes segundo sexo (ROGOL e col. 2002).

Quanto à composição corporal, a massa muscular aumenta gradualmente desde o início da aceleração do crescimento na adolescência e com os sucessivos estágios de maturação sexual, sendo o desenvolvimento muscular nessa etapa mais acentuado no sexo masculino (COLLI e col. 1993).

Em relação ao tecido adiposo, observa-se acúmulo contínuo dos 8 anos de idade até a adolescência. Porém, a velocidade de depósito de gordura diminui à medida que o crescimento esquelético acelera, atingindo valores mínimos na época em que esqueleto e musculatura têm velocidades máximas de crescimento. Essa diminuição de deposição de gordura é mais acentuada no sexo masculino, enquanto as adolescentes acumulam maior proporção da massa adiposa da idade adulta durante a puberdade, quando comparada à massa magra (ROGOL e col. 2000).

\subsection{Puberdade: desenvolvimento sexual e estado nutricional}

A adolescência é considerada um importante período do desenvolvimento do indivíduo, uma vez que mudanças fisiológicas ocorridas nesta fase têm repercussões na saúde atual e futura dos adolescentes. Durante a puberdade, estabelecem-se o padrão de gordura corporal, caracterizado pelo aumento da quantidade e redistribuição de gordura e também padrões comportamentais com influência direta na saúde dos jovens (DIETZ 1994, DIETZ 1997).

O tempo decorrente do início ao fim da puberdade varia em ambos os sexos e discute-se a relação entre o estágio de maturação sexual e características antropométricas, sugerindo que, entre as meninas, a menarca é um importante marco no aumento dos depósitos de gordura corporal. GARN e col. (1986) estudaram a relação entre idade da menarca e adiposidade de mulheres norteamericanas, concluindo que aquelas em que a ocorrência da menarca se deu em 
idade igual ou inferior aos 11 anos apresentaram-se com menor estatura e maior peso corporal, quando comparadas àquelas que apresentaram a menarca após essa idade. VAN LENTHE e col. (1996) analisaram o efeito da velocidade de maturação sexual no desenvolvimento da obesidade entre adolescentes holandeses, de ambos os sexos, acompanhando-os durante 14 anos, constatando que a maturação sexual precoce interfere no valor do índice de massa corporal, bem como na soma de pregas cutâneas, que se apresentaram elevados.

KAPLOWITZ e col. (2001) observaram maior valor de IMC em meninas norteamericanas com desenvolvimento precoce dos pêlos pubianos e mamas, em relação àquelas com desenvolvimento normal e WANG e col. (2000) mostraram que mulheres que maturaram precocemente apresentam chance duas vezes maior de serem obesas quando comparadas às que maturam normalmente.

OKASHA e col. (2001) afirmam que a menarca pode afetar a saúde da mulher, quando adulta, devido à alteração do crescimento subseqüente. Demonstraram, ainda, relação inversa entre idade da menarca e peso/IMC. Estudos citam, também, a menarca precoce como fator de risco para algumas patologias, entre elas câncer de mama, ovário, osteoporose e doença isquêmica do coração (COOPER e col. 1996, OKASHA e col. 2001).

Estudos transversais e longitudinais apontam que meninas, durante e após a puberdade, apresentam maior quantidade de massa adiposa e maior IMC que meninas pré-púberes. Entretanto, outras investigações detectaram que meninas com sobrepeso/obesidade tendem a maturar sexualmente antes daquelas com estado nutricional normal e como hipótese tem-se que o grau de gordura corporal pode engatilhar eventos neuroendócrinos que levam à menarca (FRISCH 1994).

De acordo com a hipótese de Frisch, existe uma quantidade crítica de gordura corporal necessária para a ocorrência da menarca e meninas com peso corporal 
mais elevado maturam antes que seus pares com peso menor (FRISCH 1994). Porém, embora a direção causal da associação permaneça controversa, existem grandes evidências de que o estágio de maturação sexual tem um efeito mais importante nos niveis de gordura corporal do que a gordura corporal no desenvolvimento sexual, uma vez que alterações hormonais (estrógenos) associadas à maturação sexual promovem o desenvolvimento do tecido adiposo (WANG 2002).

\subsection{Sobrepeso e obesidade: conseqüências e prevalência}

Atualmente, a obesidade como doença e fator de risco para patologias crônicas não transmissiveis, como diabetes tipo 2, hipertensão arterial, dislipidemias, doenças cardiovasculares, doenças na vesícula biliar e alguns tipos de câncer, tem sua prevalência aumentada, mundialmente e em todas as faixas etárias, consolidando-se como problema importante em saúde pública (JUNG 1997, WHO 2000).

Entende-se por obesidade o acúmulo excessivo de gordura corporal. Como o indicador mais utilizado para diagnóstico do estado nutricional em populações (indice de massa corporal) constitui medida indireta de obesidade, uma vez que não distingue as diferentes frações corporais (como massa magra e massa adiposa), denomina-se sobrepeso o excesso de peso corporal em relação à estatura (WHO 2000).

Entre as inúmeras conseqüências do sobrepeso e obesidade, sabe-se que crianças e adolescentes obesos tendem a se tornar adultos obesos e que a obesidade infanto-juvenil está associada à maior morbi-mortalidade a longo prazo. Excessivo ganho de peso durante a adolescência tem efeitos no tamanho corporal adulto, distribuição de gordura corporal e, conseqüentemente, no risco de doenças metabólicas e cardiovasculares na vida futura (WHO 2000). 
A obesidade associa-se, também, a riscos imediatos à saúde, como aumento da pressão arterial, do colesterol total e da glicose sangüínea, bem como a diversas e graves doenças crônicas como diabetes, asma, apnéia noturna e doenças da vesícula biliar. Estudos documentam aumento da prevalência de diabetes tipo 2 em crianças e adolescentes, sendo a obesidade a principal responsável por este aumento. Entre as conseqüências a curto prazo, encontram-se os efeitos psicológicos que incluem dificuldade de socialização e interação, imagem corporal distorcida e baixa auto-estima, entre outras (REILLY e col. 2003).

A população adulta norte-americana apresenta prevalência de obesidade $\left(\right.$ IMC $\geq 30 \mathrm{~kg} / \mathrm{m}^{2}$ ) de $19,9 \%$ nos homens e $24,9 \%$ nas mulheres acima de 20 anos de idade (WHO 2000). Quanto à obesidade mórbida $\left(I M C \geq 40 \mathrm{~kg} / \mathrm{m}^{2}\right)$, para a mesma faixa etária, observa-se prevalência de $4,7 \%$ para ambos os sexos, sendo $3,1 \%$ para homens e $6,3 \%$ para mulheres (FLEGAL e col. 2002).

A população infanto-juvenil norte-americana apresenta prevalências inferiores, porém igualmente elevadas às da população adulta. Para indivíduos entre 6 e 11 anos de idade, a prevalência de risco de sobrepeso (percentil $85 \leq 1 \mathrm{MC} /$ idade/sexo<percentil 95) é de 32,7 e $27,8 \%$ para meninos e meninas, respectivamente, enquanto $16,0 \%$ dos meninos e $14,5 \%$ das meninas apresentam sobrepeso (IMC/idade/sexo $\geq$ percentil 95). Em adolescentes, entre 12 e 19 anos de idade, as prevalências de risco de sobrepeso são de 30,5 e 30,2\% para o sexo masculino e feminino, respectivamente e a de sobrepeso é de $15,5 \%$ para ambos os sexos (OGDEN e col. 2002).

O diagnóstico de risco de sobrepeso e sobrepeso em crianças e adolescentes utilizado por OGDEN e col. (2002) baseou-se nas recomendações de Organização Mundial de Saúde (WHO 1995), que preconiza a utilização de pontos de corte de IMC/idade/sexo baseados nos percentis da população norteamericana. A terminologia de risco de sobrepeso e sobrepeso deve-se ao fato do IMC ser medida indireta de obesidade. 
FILOZOF e col. (2001) apontam tendência semelhante de aumento da prevalência de sobrepeso/obesidade, para população infantil e adulta, em revisão de estudos epidemiológicos realizados na América Latina, incluindo Brasil, Argentina, México, Paraguai, Peru e Chile.

No Brasil, estudos populacionais descrevem que a prevalência de sobrepeso, para a população de 6 a 18 anos de idade, triplicou, aumentando de 4,1 para 13,9\%, comparando-se dados da Pesquisa Nacional de Saúde e Nutrição PNSN e Pesquisa de Padrão de Vida - PPV dos anos de 1974/75 e 1996/97. Especificamente entre os adolescentes, de 10 a 18 anos de idade, a prevalência de sobrepeso, em 1997, foi 13,1 e $14,8 \%$ para meninos e meninas, respectivamente, sendo $8,4 \%$ na região rural e $18,4 \%$ na urbana (WANG e col. 2002)

\subsection{Sobrepeso e obesidade: etiologia}

A rápida elevação da prevalência de sobrepeso/obesidade nos últimos anos ocorreu num período muito curto de tempo para permitir atribuí-la a quaisquer mutações genéticas significativas nas populações (WHO 2000). A explicação mais provável estaria nas mudanças ocorridas na economia (industrialização e globalização) com implicações nos estilos de vida e no meio ambiente, levando a uma produção agrícola mais eficiente (disponibilidade de alimentos durante o ano inteiro a preços razoáveis), a ocupações mais sedentárias, transporte motorizado, entre outros (WHO 2000, WANG e col. 2002).

A crescente urbanização e industrialização em vários países ao redor do mundo associam-se a alterações nas dietas, aumentando a ingestão de alimentos ricos em lipídios e com alta densidade energética e a um estilo de vida sedentário. Essas alterações estão associadas ao fenômeno de transição nutricional caracterizado por modificações no estado nutricional da população e possivelmente, o responsável pelo rápido e atual aumento da prevalência de obesidade (POPKIN 2002). 
O sobrepeso/obesidade apresenta diversos fatores que interagem na sua etiologia. A patologia resulta de um processo fisiológico determinado por fatores genéticos e ambientais e sua inter-relação é conseqüência de um desequilíbrio energético que ocorre quando a absorção de energia excede o gasto durante um periodo prolongado de tempo (WHO 2000).

\subsubsection{Alimentação}

O valor energético total da dieta (VET) é determinado pela alimentação, caracterizada pela freqüência, quantidade e tipo de alimentos consumidos (WHO 2000).

A maioria dos estudos epidemiológicos com delineamento transversal, envolvendo obesidade e alimentação (caracterizada pelo VET e/ou a quantidade de macronutrientes consumidos, principalmente lipidios) apresenta resultados contraditórios. No entanto, estudos experimentais realizados com animais e estudo clínicos com humanos apontam relação forte e positiva entre VET e/ou lipídios consumidos e peso corporal (WHO 2000).

Teoricamente, fatores como saciedade, densidade energética, palatabilidade e respostas metabólicas justificariam a relação positiva entre lipidios da dieta e obesidade. Considerando-se os macronutrientes, alimentos ricos em lipídios apresentam elevada densidade energética $(9 \mathrm{kcal} / \mathrm{g})$, maior capacidade de armazenamento, alta palatabilidade, autoregulação metabólica relativamente fraca e provocam menor saciedade quando comparados aos alimentos ricos em proteínas e carboidratos, conforme apresentado no quadro 1 (WHO 2000). 
Quadro 1 - Caracteristicas dos macronutrientes.

\begin{tabular}{|l|c|c|c|}
\hline Característica & Proteína & Carboidratos & Lipidio \\
\hline Habilidade de regular a fome e saciedade & Alta & Alta & Baixa \\
Contribuição para o VET da dieta & Baixa & Alta & Alta \\
Densidade energética & Baixa & Baixa & Alta \\
Capacidade de armazenamento corporal & Baixa & Baixa & Alta \\
Autoregulação & Excelente & Excelente & Pobre \\
(capacidade de estimular a própria oxidação) & & & \\
\hline
\end{tabular}

Fonte: WHO, 2000.

Fatores como 0 padrão alimentar e 0 tamanho da porção dos alimentos/preparações consumidas podem constituir potenciais fatores de risco para o ganho de peso (GORAN 1998, FUNG e col. 2001).

Entre a população adolescente, estudos sobre alimentação descrevem um padrão caracterizado por excessivo consumo de alimentos com elevada densidade energética como doces, chocolates e refrigerantes e por baixo consumo de hortaliças, frutas e produtos lácteos. Durante a adolescência, destaca-se a influência crescente dos amigos, mídia e modismos nos hábitos alimentares (GAMBARDELLA e col. 1999, CAVADINI e col. 1999).

\subsubsection{Atividade física e sedentarismo}

O gasto energético pode ser dividido em duas frações principais: a taxa de metabolismo basal e a energia despendida com atividades físicas que incluem a ocupacional, de locomoção, de lazer e recreacional e atividade física estruturada (exercício físico), incluindo tipo, intensidade, freqüência e duração destas atividades (WHO 2000).

O maior componente do gasto energético é o gasto em repouso ou taxa de metabolismo basal - TMB - que corresponde a aproximadamente $75 \%$ do gasto energético total - GET - da maioria dos indivíduos. O componente que mais varia 
no GET é proveniente do gasto energético com atividade física e consiste na variável chave para quantidade de energia despendida pelo indivíduo (JAKICIC 2002).

Estudos epidemiológicos descrevem relação inversa entre o gasto energético com atividade física e a prevalência de diversas patologias, incluindo as morbidades cardiovasculares, diabetes tipo 2 e alguns tipos de câncer (HARDMAN 2001). A redução da prática de atividade física resultaria na diminuição do GET, favorecendo o estabelecimento do sobrepeso/obesidade (GRUND e col. 2001).

Entretanto, a relação inversa entre obesidade e gasto energético/atividade física não apresenta consenso na literatura. BALL e col. (2001) verificaram, em meninos, relação inversa e significante entre $\mathrm{IMC}$ /quantidade absoluta e relativa de gordura corporal e dois indicadores referentes à atividade físicas: o nível de atividade física (GET $\div \mathrm{TMB}$ ) e o gasto energético com atividade física (GETXTMB). Para as meninas, não foram observadas relações significativas entre as variáveis citadas.

Vale ressaltar que a relação entre atividade física e obesidade pode ser de causa ou efeito, uma vez que indivíduos obesos podem ser menos ativos devido à presença da patologia ou o baixo nível de atividade física pode ser causa da obesidade (GORAN e col. 1998, WHO 2000).

A relação entre assistir televisão e obesidade em crianças e adolescentes tem sido tópico de interesse e debate desde sua investigação pioneira, em 1985, que constatou relação positiva entre a prevalência de obesidade em adolescentes de 12 a 17 anos de idade e o número de horas/dia assistindo televisão (DIETZ e GORTMAKER 1985) 
Desde então, estudos epidemiológicos sugerem que a inatividade física ou sedentarismo, caracterizado por atividades fisicas de lazer passivas que incluem assistir televisão, jogar vídeo game e utilizar o computador, exerce influência no desenvolvimento da obesidade (GORAN 1998, FRUTUOSO e col. 2003).

PRENTICE e JEBB (1995) sugerem que o decréscimo da atividade física e/ou aumento do sedentarismo (tempo gasto assistindo televisão e o número de carros por família) tem importante papel no ganho de peso e desenvolvimento da obesidade.

O efeito de assistir televisão no ganho de peso está vinculado à diminuição da prática de atividade física e ao aumento do valor energético total da dieta, pois os indivíduos tendem a ingerir alimentos enquanto assistem televisão, além de permanecerem expostos à publicidade de alimentos por ela veiculados, nem sempre de adequada qualidade nutricional. Entretanto, igualmente à atividade física, investigações apontam que o sedentarismo pode ser tanto causa quanto conseqüência da obesidade (BERKEY e col. 2000, GRUND e col. 2001, STEINBECK 2001).

GRUND e col. (2001) ressaltam, ainda, que o tempo despendido com atividades físicas pode ser influenciado por diversos fatores como clima, estrutura familiar, nível sócio-econômico, segurança e acesso a áreas de lazer e modismos.

\subsubsection{Nivel sócio-econômico (NSE)}

O nível sócio-econômico de uma população pode ser medido por meio de renda, educação, ocupação e, em alguns países, local de residência (rural/urbana) e estudos apontam diferentes associações entre obesidade e NSE segundo países desenvolvidos e em desenvolvimento (WHO 2000).

WANG (2001) comenta sobre a relação inversa entre NSE e obesidade em mulheres de sociedades desenvolvidas, embora esta relação seja inconsistente 
entre homens e crianças. Por outro lado, em sociedades em desenvolvimento, existe forte relação positiva entre NSE e obesidade em mulheres, homens e crianças.

A relação entre obesidade em crianças e adolescentes norte-americanas e NSE mostrou que seguimentos de baixo NSE apresentam maior risco para obesidade, ao contrário da China, país no qual indivíduos de alto NSE têm maior risco para desenvolver obesidade, possivelmente devido às diferentes influências do NSE no estilo de vida (hábitos alimentares e de atividade física) da população destes países (WANG 2001).

Em sociedades em desenvolvimento, menores prevalências observadas em indivíduos de baixo NSE, quando comparadas aos de NSE mais altos, podem estar vinculadas ao limitado acesso aos alimentos e à elevada atividade física ocupacional. Em países desenvolvidos, o aumento da renda pode ser destinado à maior prática de atividade física e escolha de alimentos mais saudáveis, justificativa coerente, também, para a relação inversa entre nível de escolaridade e obesidade (WHO 2000).

Estudo realizado no Brasil, indica que mulheres adultas mostraram-se mais obesas que os homens, em todas as regiões e estratos econômicos estudados. Em 1997, a prevalência de obesidade entre aquelas pertencentes ao quartil de maior renda foi aproximadamente o dobro das pertencentes ao quartil de menor renda, na região Nordeste do país, confirmando a relação positiva entre NSE e obesidade observada nos países em desenvolvimento. No entanto, o inverso foi observado na região Sul do país, caracterizando tendência de alteração da relação entre NSE e obesidade (MONTEIRO e col. 2002). 


\subsubsection{Fatores genéticos}

Estudos epidemiológicos, genéticos e de biologia molecular sugerem diferentes suscetibilidades entre individuos no desenvolvimento da obesidade, patologia com etiologia complexa e multifatorial (ROSENBAUM e LEIBEL 1998).

O componente hereditário da obesidade consiste na fração da variação populacional da doença que pode ser explicada pela transmissão genética. Estudos realizados com várias gerações de uma mesma família, irmãos biológicos, gêmeos e filhos adotivos documentam que os níveis de hereditariedade para valores de IMC variam entre 25 e $40 \%$ e para gordura abdominal entre 50 e $60 \%$ (WHO 2000).

FRISANCHO (2000) demonstrou que crianças, filhas de pais obesos, apresentam $80 \%$ de chance de serem obesas, enquanto crianças, filhas de pais eutróficos, apresentam apenas $10 \%$ de chance. EBBELING e col. (2002) discutem que interações entre pais e filhos e 0 ambiente familiar podem afetar os comportamentos relacionados ao risco do desenvolvimento de sobrepeso/obesidade e ressaltam, ainda, que a influência do estado nutricional dos pais pode refletir aspectos ambientais e genéticos e que, durante a adolescência, observa-se influência crescente dos pares.

\subsubsection{Outros fatores}

Uma série de fenômenos fisiológicos contribuem para maior depósito de gordura em mulheres, quando comparadas aos homens, sendo o sexo um importante fator biológico com influência marcante no ganho de peso e desenvolvimento da obesidade, assim como outros fatores, como tabagismo, alcoolismo, aleitamento materno e raça (WHO 2000).

Alguns autores referem a existência de períodos críticos para o desenvolvimento da obesidade, como: período prenatal, adiposity rebound (5-7 anos de idade), adolescência, gestação e menopausa (DIETZ 1994, DIETZ 1997, WHO 2000). 
Durante o periodo prenatal, a nutrição fetal contribui diretamente para o desenvolvimento do tamanho, forma e composição corporais, bem como à competência metabólica relacionada aos macronutrientes (WHO 2000). Estudos apontam relações entre crescimento intra-uterino e risco de obesidade, adiposidade abdominal e suas comorbidades futuras (SEIDMAN e col. 1991, BARKER e col. 1997).

DAVISON e BIRSCH (2001) propõem um modelo de causalidade para a obesidade em crianças e adolescentes. A patologia resultaria da interação entre o individuo e familia/escola que por sua vez seria influenciada por características da sociedade e da comunidade, conforme apresentado no quadro 2.

Quadro 2 - Variáveis que influenciam o peso corporal de crianças e adolescentes.

Características relacionadas à:

Crianca e adolescente: idade, sexo, suscetibilidade familiar, consumo alimentar, atividade física, sedentarismo

Pais e familia: interações com amigos e irmãos, preferências e padrões familiares de atividade física e alimentação, estado nutricional dos pais, conhecimento sobre nutrição, alimentos disponiveis em casa

Comunidade, sociedade e demografia: nível sócio-econômico, segurança, atividade de lazer, acesso à recreação, atividade física e alimentação na escola, acesso aos alimentos e restaurantes, raça

Fonte: DAVISON e BIRSCH (2001)

A complexidade na determinação das causas da obesidade, dentre os inúmeros fatores que interagem em sua etiologia, evidencia a importância do desenvolvimento de estratégias efetivas para sua prevenção.

Conforme mencionado, a adolescência pode ser considerada etapa de importantes alterações biopsicossociais na qual estabelecem-se comportamentos 
relacionados à prática alimentar e de atividade física, fatores de risco para obesidade, que podem persistir por toda a vida.

Embora existam investigações mostrando que a obesidade em crianças e adolescentes aumenta o risco de persistência da patologia na vida adulta, pouco se conhece sobre as relações entre as alterações da composição corporal ocorridas na puberdade e o risco de estabelecimento futuro de sobrepeso e obesidade, bem como os fatores associados a tais modificações (WANG e col. 2000).

Uma vez que a puberdade constitui período crítico do desenvolvimento, com rápido crescimento acompanhado por alterações na composição corporal, este trabalho visa a analisar os fatores associados ao sobrepeso e obesidade em crianças e adolescentes de 8 a 18 anos de idade. 
OBJETIVO 


\section{OBJETIVO GERAL}

Analisar os fatores associados ao sobrepeso e obesidade de crianças e adolescentes de 8 a 18 anos de idade.

\subsection{Objetivos especificos}

- descrever a amostra estudada segundo variáveis sócio-econômicas e demográficas.

- descrever os valores transversais do IMC e gordura corporal dos indivíduos estudados, segundo estágios de desenvolvimento sexual, idade e nível sócioeconômico.

- analisar os fatores associados aos valores transversais do IMC e gordura corporal da amostra em estudo.

- analisar os fatores associados ao sobrepeso e obesidade da amostra em estudo.

- descrever as variações temporais do IMC e gordura corporal dos indivíduos estudados, segundo estágios de desenvolvimento sexual, idade e nível sócioeconômico.

- analisar os fatores associados às alterações temporais do IMC e gordura corporal da amostra em estudo. 
HIPÓTESES 


\section{HIPÓTESES}

- As variáveis atividade física, sedentarismo e o valor energético total da dieta constituem fatores associados às variações temporais do índice de massa corporal e gordura corporal na população estudada.

- A idade e nível sócio-econômico são determinantes nas alterações temporais do índice de massa corporal e gordura corporal, diferentemente no sexo feminino e masculino.

- O nivel sócio-econômico constitui importante preditor do risco de sobrepeso e obesidade na população estudada. 
MATERIAL E MÉTODOS 


\section{MATERIAL E MÉTODOS}

\subsection{Delineamento, população e local de estudo}

Foi criada coorte prospectiva, com indivíduos de 8 a 18 anos de idade, de ambos os sexos, que participaram de 3 coletas de dados, durante o período de um ano, com intervalo de 6 meses entre as mesmas. A primeira coleta foi realizada em agosto/setembro de 2001, a segunda, em março/abril e a última, em setembro/outubro, ambas em 2002.

Foram estudados individuos matriculados em uma escola pública e uma privada do Município de São Paulo, com o intuito de obter populações de diferentes níveis sócio-econômicos. Devido ao início precoce da puberdade, foram incluidas meninas de 8 e 9 anos de idade.

\subsection{Coleta de dados}

A coleta de dados foi realizada somente pela pesquisadora, por meio de entrevistas e por mensuração antropométrica e exame de impedância bioelétrica, nas próprias instituições, sendo os dados registrados em formulários pré-testados (Anexo 1).

Dados referentes ao nível sócio-econômico, estado nutricional dos pais e peso ao nascer foram obtidos por meio de questionário enviado aos pais (Anexo 2), juntamente com termo de consentimento. As crianças e adolescentes receberam informações sobre esse questionário com o intuito de esclarecer possiveis dúvidas relativas ao seu preenchimento.

\subsubsection{Variáveis estudadas}

As variáveis dependentes estudadas foram as seguintes: 


\section{- Índice de massa corporal das crianças e adolescentes}

Para a mensuração do peso corporal foi utilizada balança eletrônica do tipo plataforma (Tanita ${ }^{\circledR}$ ), com capacidade para $150 \mathrm{~kg}$ e graduação em $100 \mathrm{~g}$, e para a da estatura foi utilizado antropômetro (Seca ${ }^{\$}$ ), com escala em milimetros, fixado em suporte de madeira, seguindo metodologia proposta por GORDON e col. (1988).

Foi calculado o índice de massa corporal $\left(\mathrm{IMC}=\right.$ peso/estatura $\left.{ }^{2}\right)$ e $\circ$ valor da primeira coleta, denominado valor transversal, constituiu variável dependente, do tipo contínua, no presente estudo.

- Composição corporal - quantidade de massa magra e gordura corporal.

Para a determinação dos valores absolutos e relativos de gordura corporal foi utilizado aparelho de impedância bioelétrica RJL Systems ${ }^{\circledR}$ adotando-se as técnicas propostas pelo fabricante, segundo manual de instruções (RJL SYSTEMS 2000). Os valores transversais, absoluto e relativo, da primeira coleta constituiram duas variáveis dependentes, do tipo contínua.

A técnica da impedância bioelétrica - BIA - consiste na emissão de uma corrente de $50 \mathrm{kHz}$ e mensuração da impedância corporal, definida como a oposição de um condutor à passagem de uma corrente, sendo que no corpo humano, a quantidade de eletricidade conduzida é proporcional ao total de ions contidos no meio condutor (LUKASKI 1987).

O primeiro passo é a determinação da quantidade de água corporal a partir do valor da impedância obtido. A seguir, determina-se a quantidade de massa magra por meio de equações preditivas e o total de gordura corporal, é, posteriormente, obtido pela diferença entre o peso do indivíduo e a quantidade de massa magra calculada (FOSTER e LUKASKI 1996, HOUTKOOPER e col. 1996). 


\section{- Sobrepeso e obesidade das crianças e adolescentes}

A presença de sobrepeso e obesidade foi verificada, entre as crianças e adolescentes estudados, segundo pontos de corte de IMC/idade e sexo, propostos por COLE e col. (2000), apresentados no Quadro 3. Sobrepeso e obesidade foram duas variáveis dependentes do tipo categórica (sendo $0=$ ausência e 1 = presença).

Quadro 3 - Pontos de corte de IMC para sobrepeso e obesidade segundo sexo e idade.

\begin{tabular}{|ccccc|}
\hline Idade (anos) & \multicolumn{2}{c}{ Sobrepeso } & \multicolumn{2}{c|}{ Obesidade } \\
\cline { 2 - 5 } & Homens & Mulheres & Homens & Mulheres \\
\hline 8 & 18,44 & 18,35 & 21,60 & 21,57 \\
8,5 & 18,76 & 18,69 & 22,17 & 22,18 \\
9 & 19,10 & 19,07 & 22,77 & 22,81 \\
9,5 & 19,46 & 19,45 & 23,39 & 23,46 \\
10 & 19,84 & 19,86 & 24,00 & 24,11 \\
10,5 & 20,20 & 20,29 & 24,57 & 24,77 \\
11 & 20,55 & 20,74 & 25,10 & 25,42 \\
11,5 & 20,89 & 21,20 & 25,58 & 26,05 \\
12 & 21,22 & 21,68 & 26,02 & 26,67 \\
12,5 & 21,56 & 22,14 & 26,43 & 27,24 \\
13 & 21,91 & 22,58 & 26,84 & 27,76 \\
13,5 & 22,27 & 22,98 & 27,25 & 28,20 \\
14 & 22,62 & 23,34 & 27,63 & 28,57 \\
14,5 & 22,96 & 23,66 & 27,98 & 28,87 \\
15 & 23,29 & 23,94 & 28,30 & 29,11 \\
15,5 & 23,60 & 24,17 & 28,60 & 29,29 \\
16 & 23,90 & 24,37 & 28,88 & 29,43 \\
16,5 & 24,19 & 24,54 & 29,14 & 29,56 \\
17 & 24,46 & 24,70 & 29,41 & 29,69 \\
17,5 & 24,73 & 24,85 & 29,70 & 29,84 \\
18 & 25 & 25 & 30 & 30 \\
\hline
\end{tabular}

Fonte: COLE e col. (2000) 
- Variação temporal de IMC e gordura corporal

As variações temporais de IMC e gordura corporal ( $\mathrm{kg} \mathrm{e} \%$ ) constituíram três variáveis dependentes do tipo contínua, calculadas pela diferença entre as medidas ( $3^{\mathrm{a}}$ coleta $-1^{\mathrm{a}}$ coleta) ajustadas pelo intervalo de tempo entre as medições.

As variáveis independentes estudadas foram as seguintes:

- Nível sócio-econômico: renda familiar e escolaridade materna

Foi obtida a renda familiar total, em salários mínimos, bem como o número de pessoas que vivem na mesma residência, além da escolaridade e materna.

\section{- Peso ao nascer das criancas e adolescentes}

Foi solicitado aos pais informar o peso ao nascer do(a) seu(sua) filho(a).

\section{- Índice de massa corporal dos pais}

Os pais informaram seus respectivos pesos e estaturas, para sua classificação, segundo estado nutricional. Com o intuito de corrigir a informação referida, foram realizadas medições de peso e estatura em uma sub-amostra de mães que participaram de reuniões de pais e mestres ocorridas no segundo semestre de 2002. Os equipamentos e as técnicas de mensuração foram os mesmos utilizados para as crianças e adolescentes.

Participaram das medições 167 mães, tendo sido criado modelo para correção de peso e estatura materna referida. Não foi possível criar um modelo de correção para os pais devido à pequena participação destes às reuniões em que foram colhidas as medidas e da freqüente impossibilidade dos pais presentes participarem das coletas.

Comparando os dados das mães, utilizados para a formulação dos modelos de correção ( $n=167$ ), as médias (desvios-padrão) do peso materno referido e medido 
foram, respectivamente $66,0 \mathrm{~kg}(10,24)$ e $66,3 \mathrm{~kg}(10,00)$. Para estatura, as médias foram de $161,3 \mathrm{~cm}(6,53)$ e $160,8 \mathrm{~cm}(6,21)$ para referida e medida, respectivamente, com diferença estatisticamente significante. As diferenças entre os pesos variaram de $-4,3$ a $+5,1 \mathrm{~kg}$, sendo a diferença média de $-0,23 \mathrm{~kg}$. Para a estatura, a média das diferenças foi de $+0,47 \mathrm{~cm}$, variando de $-3,0 \mathrm{a}+3,1 \mathrm{~cm}$.

Quadro 4 - Modelos de correção para peso e estatura materna referidos.

\begin{tabular}{|c|}
\hline Equação \\
\hline Peso referido $=-0,97+1,01 \times$ peso medido \\
\hline Estatura referida $=-6,07+1,04 \times$ estatura medida \\
\hline
\end{tabular}

As variáveis antropométricas paternas não foram corrigidas $e$, portanto, não foram utilizadas na construção dos modelos. Para as mães dos indivíduos estudados, foi calculado o índice de massa corporal (a partir dos valores corrigidos de peso e estatura) que constituiu variável independente deste estudo.

\section{- Idade das crianças e adolescentes}

A idade foi obtida por meio da diferença entre as datas da entrevista e de nascimento de cada indivíduo.

\section{- $\underline{\text { Sobrepeso e obesidade das mães }}$}

A presença de sobrepeso e obesidade foi verificada, entre as mães dos indivíduos estudados por meio dos pontos de corte recomendados pela Organização Mundial de Saúde, sendo $I M C \geq 25$ para classificação de sobrepeso e IMC $\geq 30$ para obesidade (WHO 2000).

\section{- Estágio de maturação sexual e menarca}

Em publicação sobre a utilização e interpretação de medidas antropométricas para a avaliação do estado nutricional de populações, a Organização Mundial de Saúde aponta diversas opções para o estadiamento sexual de adolescentes. 
Entre elas: idade óssea, número de dentes permanentes, menarca, espermarca, presença de voz adulta, pico de velocidade de crescimento e desenvolvimento dos caracteres sexuais secundários (WHO 1995).

A escolha do método de avaliação do estágio de maturação sexual - EMS - de adolescentes a ser utilizado dependerá de fatores como recursos humanos, financeiros, facilidade/praticidade na avaliação e fatores culturais. Neste contexto, a auto-avaliação do desenvolvimento dos caracteres secundários constitui alternativa eficiente para o estadiamento sexual em estudos populacionais (WHO 1995).

Para determinação do EMS, foi realizada auto-avaliação baseada na identificação desse estágio a partir da comparação com fotos de 5 etapas que caracterizam o desenvolvimento sexual da criança e adolescente, conforme critério proposto por Tanner, citado por COLLI e col. (1993). O desenvolvimento dos pêlos pubianos (P1, P2, P3, P4, P5) foi avaliado em ambos os sexos, segundo caraterísticas, quantidade e distribuição. Para o sexo masculino, considerou-se o estágio de desenvolvimento dos genitais (G1, G2, G3, G4, G5) e para o feminino, o desenvolvimento das mamas (M1, M2, M3, M4, M5), avaliados conforme o tamanho, forma e características.

As crianças e adolescentes foram distribuidos em grupos pequenos, de mesmo sexo, e receberam informações sobre adolescência, desenvolvimento físico e maturação sexual e, em seguida, explicações sobre a auto-avaliação e o preenchimento do formulário (Anexo 3).

Para auxiliar as crianças e adolescentes na auto-avaliação foram fornecidas informações sobre as características que diferenciam os diferentes estágios de maturação sexual, conforme apresentado por COLLI e col. (1993). Como exemplo, pode-se citar a diferença entre os estágio M1 e M2 do desenvolvimento das mamas. No segundo, observa-se o broto mamário caracterizado pelo 
aumento da glândula mamária, com elevação da auréola e papila, formando um pequena saliência, que não é encontrada no primeiro estágio.

Alguns indivíduos poderiam estar em fases diferentes para cada uma destas características (por exemplo M4P5 ou G2P1), visto que a maturação das mesmas obedece a mecanismos hormonais e genéticos diferentes (COLLI e col. 1993). Desta forma, adotou-se como critério de desenvolvimento o menor estágio de maturação sexual entre pêlos pubianos e genitais para os meninos e mamas e pêlos pubianos para as meninas.

Para as meninas, foi indagada a ocorrência da menarca e, em caso afirmativo, a idade em que havia ocorrido.

\section{- Atividade física}

Técnicas envolvendo água duplamente marcada, monitoramento da freqüência cardiaca e acelerômetros são usadas para determinação do GET, TMB e gasto energético com atividades físicas em estudos realizados em alguns países. No entanto, constituem métodos onerosos e de difícil realização, pois requerem profissionais especializados e infra-estrutura adequada (GRUND e col. 2001).

Desta forma, o esforços para desenvolvimento e utilização de questionários são constantes em estudos epidemiológicos por serem de fácil aplicação e baixo custo. Entretanto, apresentam aspectos negativos, pois dependem da habilidade do indivíduo no preenchimento das questões e da transformação das informações referidas em gasto energético (GORAN 1998).

Para a quantificação da atividade fisica praticada, foram solicitadas informações sobre prática de atividades físicas de lazer, incluindo as aulas de educação física curriculares e prática de exercício físico estruturado (academias, treinamento em esportes, clubes) e o tipo, freqüência e duração das atividades (Anexo 1). Criouse um escore de atividade física, definido como a soma do número de horas 
diárias praticando atividades físicas.

\section{- $\underline{\text { Sedentarismo }}$}

Investigou-se a prática de atividades físicas de lazer passivas, entendidas como a freqüência e duraçăo de atividades como assistir televisão, jogar vídeo game e utilizar o computador. Indagou-se o número de horas de sono de cada indivíduo (Anexo 1). Criou-se um escore de sedentarismo composto pela soma do número de horas diárias assistindo televisão, jogando vídeo game e utilizando o computador.

\section{- Consumo alimentar}

Foram realizados dois recordatórios de 24 horas (R-24h) com o objetivo de obter informações sobre a quantidade de lipidios ingeridos e o VET da dieta consumida pelas crianças e adolescentes. Os R-24h foram coletados em dias não consecutivos com o auxílio de álbum fotográfico (ZABOTTO e col. 1996) e utensílios domésticos, para melhor descrição da porção consumida.

Os inquéritos alimentares foram realizados durante a última coleta, devido a maior facilidade operacional e com 0 intuito de evitar que as crianças e adolescentes alterassem seus hábitos alimentares em função da realização da coleta, caso fosse realizada anteriormente.

Para o cálculo do valor energético total de dieta e da quantidade de lipídios consumida criou-se planilha com informações nutricionais do Estudo Nacional de Despesa Familiar - ENDEF (IBGE 1996). Foi incluida a composição nutricional de alimentos industrializados fornecida pelos fabricantes.

O consumo de lipídios foi ajustado pelo VET da dieta conforme método proposto por WILLET e col. (1997). Foram usados os resíduos da regressão na qual a variável dependente foi a quantidade de lipídios consumida e a independente 0 
VET da dieta. O VET da dieta foi incluído em todos os modelos estudados, juntamente com a quantidade de lipídios ajustada, como variável de controle.

\subsection{Análise de dados}

\subsubsection{Análise estatística}

Para a descrição das variáveis foram utilizadas medidas de tendência central e dispersão. Utilizaram-se testes t de Student e de Kruskal-Wallis para comparação entre as médias dos grupos e os testes de associações entre as variáveis foram obtidos segundo a distribuição qui-quadrado e por meio do teste exato de Fischer. Estabeleceu-se nível de significância de 5\% para os testes estatísticos.

Foram excluídos das análises os indivíduos que apresentaram valores transversais e variações temporais de IMC, gordura corporal ( $\mathrm{kg} \mathrm{e} \%$ ) discrepantes, sendo superiores a 3 escores $z$ ou inferiores a -3 escores $z$.

Para verificar a relação entre as variáveis dependentes e as independentes, foi utilizado o coeficiente de correlação de Pearson. Os cálculos estatísticos foram realizados com o auxílio do programa Stata 6.0 (STATACORP 1999) e as análises estatísticas foram baseadas em diferentes modelos de regressão.

$\mathrm{Na}$ análise transversal (dados da primeira coleta), por meio de análise de regressão linear múltipla, avaliou-se a contribuição das variáveis independentes para IMC (escore $z$ ) e quantidades absoluta e relativa de gordura corporal (logaritmo). Os resultados foram apresentados como coeficiente de regressão, erro padrão e intervalo de confiança do coeficiente.

Com os dados transversais foi realizada, ainda, regressão logística, sendo a variável dependente a presença ou ausência de sobrepeso e obesidade das crianças e adolescentes. Foram apresentados os valores de odds ratios e seus respectivos intervalos de confiança. 
$\mathrm{Na}$ análise longitudinal, estudou-se a variação temporal do IMC e gordura corporal ( $\mathrm{kg}$ e \%). Tal variação, representando variável do tipo contínua, foi analisada utilizando o método de regressão linear múltipla.

\subsection{Amostra}

Considerou-se a análise estatística a ser realizada, que consistiu, basicamente em modelos de regressão, para o cálculo da amostra. Foram incluídos 30 indivíduos em cada estrato, considerando as variáveis sexo, estágio de maturação sexual e nível sócio-econômico.

Desta forma, as variáveis sexo ( 2 grupos = masculino e feminino), estágio de maturação sexual ( 5 grupos = estágio I, II, III, IV e V) e nível sócio-econômico (2 grupos = baixo e alto) forneceram 20 estratos. Multiplicando-se o número de estratos pelo número de indivíduos em cada um deles, obteve-se amostra de 660 crianças e adolescentes, com um acréscimo de $10 \%$ referente às possiveis perdas.

\subsection{Questões éticas}

O projeto de pesquisa está de acordo com as normas da resolução 196 de 10/10/1996 do Conselho Nacional de Saúde, que regulamenta as pesquisas envolvendo seres humanos e foi aprovado pelo Comitê de Ética em Pesquisa da Faculdade de Saúde Pública da Universidade de São Paulo (Anexo 4).

Por se tratar de população vulnerável e de autonomia reduzida, solicitou-se, previamente, o consentimento livre e esclarecido da Instituição (Anexo 5). Os pais ou responsáveis legais firmaram concordância por escrito (Anexo 6). 
RESULTADOS 


\section{RESULTADOS}

\subsection{Descrição da amostra estudada}

A primeira coleta realizada contou com um total de 660 crianças e adolescentes, sendo $57,4 \%$ do sexo feminino e $42,6 \%$ do masculino. A segunda coleta apresentou 629 individuos (59,1\% de meninas e o restante meninos). No total, após a terceira coleta, foram acompanhados 617 crianças e adolescentes, sendo $40,7 \%(n=251)$ meninos e $59,3 \%(n=366)$ meninas. Observou-se maior perda entre o sexo masculino quando comparada ao feminino e as perdas foram, em sua maioria, de alunos que saíram da escola. Para as análises, foram considerados somente os dados da primeira e terceira coletas, devido ao intervalo de um ano entre estas medições.

Apesar da pequena perda de dados antropométricos e de composição corporal obtida $(6,6 \%$ da amostra inicial), ocorreu perda relacionada às informações solicitadas aos pais. Todos os indivíduos que participaram do estudo apresentaram consentimento de seus pais, entretanto alguns questionários estavam incompletos devido ao fato das crianças e adolescentes não residirem com os pais ou somente com o pai ou a mãe

Desta forma, do total de 617 indivíduos, apenas 316 meninas e 167 meninos apresentaram os questionários devidamente respondidos sobre antropometria materna, peso ao nascer, escolaridade e renda. Dado a necessidade destes dados para a construção dos modelos excluiram-se todas as crianças e adolescentes que apresentaram questionários incompletos, fato que acarretou perda total de $26,8 \%$. Além disso, somente os indivíduos com questionários completos realizaram os inquéritos alimentares, durante a terceira coleta de medidas. A Figura 1 mostra a dinâmica da coorte estudada considerando os indivíduos estudados e as perdas. 


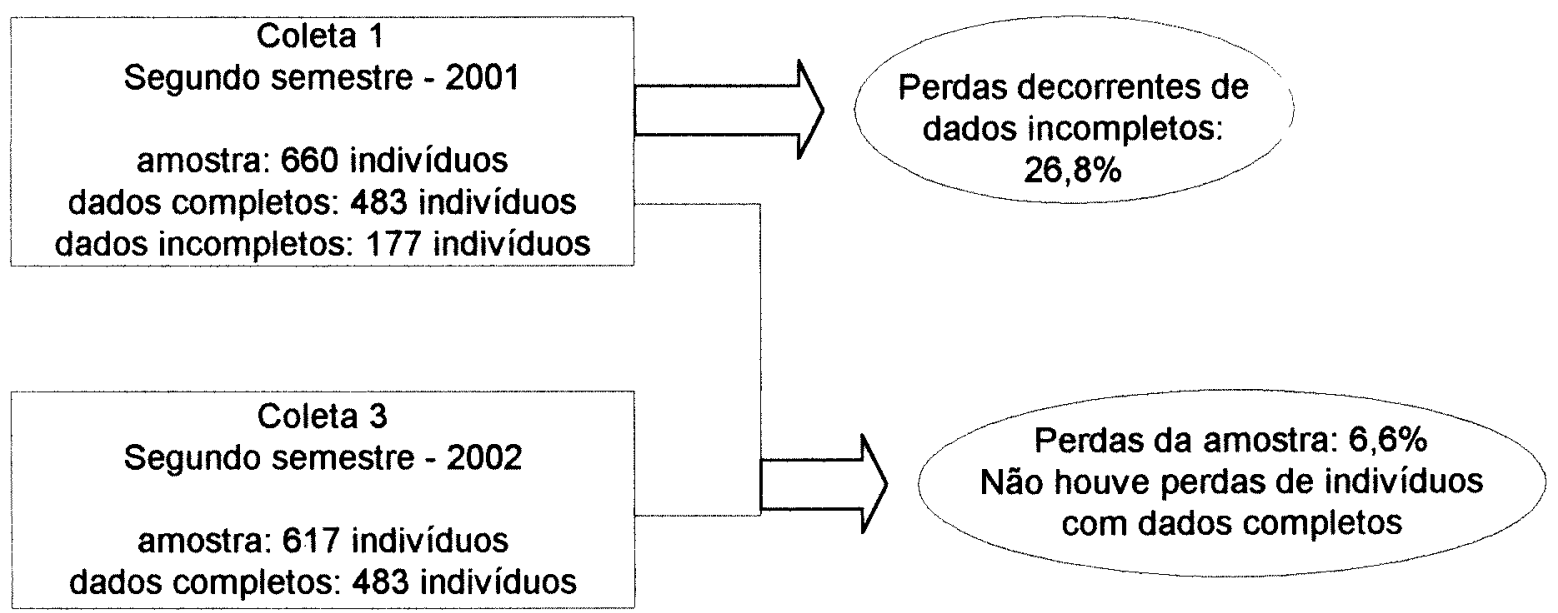

Figura 1 - Dinâmica da coorte estudada.

O intervalo entre a primeira e última coletas variou de 357 a 433 dias, sendo o intervalo médio de $391,8(15,46)$. Quanto à idade, a média na primeira coleta foi $153,3(20,15)$ e $154,6(21,6)$ meses, para meninos e meninas, respectivamente. $\mathrm{Na}$ terceira coleta, a média de idade para os meninos foi $165,4(20,34)$ meses e para as meninas, $167,6(21,85)$ meses.

Para todas as análises realizadas (transversal e longitudinal), a amostra total compôs-se de 483 crianças e adolescentes. Comparando-se os dados transversais dos indivíduos que fizeram parte do seguimento $(n=483)$ com os indivíduos com dados incompletos, que foram excluídos ( $n=177$ ), não foram observadas diferenças estatisticamente significantes em relação ao IMC e gordura corporal ( $\mathrm{kg}$ e \%). A Tabela 1 descreve as variáveis dependentes estudadas na primeira e terceira coletas. 
Tabela 1 - Distribuição das variáveis dependentes - média (desvio-padrão) segundo sexo e coleta realizada.

\begin{tabular}{|c|c|c|c|c|}
\hline \multirow[t]{2}{*}{ Variável } & \multicolumn{2}{|c|}{$1^{2}$ coleta $(n=483)$} & \multicolumn{2}{|c|}{$3^{a}$ coleta $(n=483)$} \\
\hline & क् & $\delta$ & q & $\delta$ \\
\hline$n$ & 290 & 163 & 290 & 163 \\
\hline \multicolumn{5}{|c|}{ Antropométricas } \\
\hline Peso (Kg) & $48,9(12,05)$ & $49,6(15,13)$ & $52,4(11,16)$ & $53,2(14,45)$ \\
\hline Estatura $(\mathrm{m})$ & $153,4(8,21)$ & $154,8(12,45)$ & $157,4(7,25)^{\star}$ & $159,4(11,37)$ \\
\hline IMC $\left(\mathrm{kg} / \mathrm{m}^{2}\right)$ & $20,6(3,84)$ & $20,4(4,40)$ & $21,0(3,50)$ & $20,7(4,19)$ \\
\hline \multicolumn{5}{|c|}{ Composição corporal } \\
\hline \multicolumn{5}{|c|}{ Gordura corporal } \\
\hline $\mathrm{Kg}$ & $10,9(5,48)^{*}$ & $9,8(6,01)$ & $13,2(6,05)$ & $12,9(7,05)$ \\
\hline$\%$ & $21,4(6,10)^{\star}$ & $18,7(6,68)$ & $24,2(6,19)$ & $23,1(6,93)$ \\
\hline \multicolumn{5}{|c|}{ Estado nutricional } \\
\hline \multicolumn{5}{|c|}{ Prevalência (\%) } \\
\hline Sobrepeso & 26,3 & 28,7 & 21,3 & 27,7 \\
\hline Obesidade & 7,3 & 12,6 & $3,6^{\star}$ & 10,1 \\
\hline
\end{tabular}

${ }^{*} p<0,05$

Baseando-se nos dados da primeira coleta (Tabela 1), observou-se diferença estatisticamente significante para as quantidades absoluta e relativa de massa adiposa, entre os sexos. Meninas apresentaram maior quantidade de gordura corporal ( $\mathrm{kg} \mathrm{e} \mathrm{\% )} \mathrm{em} \mathrm{relação} \mathrm{aos} \mathrm{meninos.} \mathrm{Em} \mathrm{relação} \mathrm{à} \mathrm{terceira} \mathrm{coleta,}$ verificou-se diferença para estatura e prevalência de obesidade, entre meninas e meninos $(p<0,05)$. Indivíduos do sexo masculino apresentaram maior prevalência de obesidade quando comparados aos do sexo feminino.

A comparação entre as duas coletas revelou diferença significativa para todas as variáveis estudadas $(p<0,05)$. Das 83 meninas que apresentaram sobrepeso na primeira coleta, 66 mantiveram seu estado nutricional, enquanto das 23 obesas, 11 continuavam obesas na terceira coleta. Entre os 48 meninos com sobrepeso e os 21 obesos, 44 e 16 continuaram com sobrepeso e obesidade, respectivamente. 
A Tabela 2 descreve as variáveis independentes estudadas na primeira e terceira coletas.

Tabela 2 - Distribuição das variáveis independentes - média (desvio-padrão) segundo sexo e coleta realizada.

\begin{tabular}{lcccc}
\hline Variável & \multicolumn{2}{c}{$\mathbf{1}^{\text {a }}$ coleta $(n=483)$} & \multicolumn{2}{c}{$3^{\text {a }}$ coleta $(n=483)$} \\
\cline { 2 - 5 } & $q$ & $\delta$ & 9 & $\delta$ \\
\hline$n$ & 290 & 163 & 290 & 163
\end{tabular}

Demográficas, econômicas e antropométricas

$\begin{array}{lcccc}\text { Idade (meses) } & 154,6(21,34) & 153,4(19,53) & 167,5(21,76) & 166,4(20,05) \\ \text { Renda per capita } & 2,2(1,76) & 2,2(1,85) & - \\ \text { Peso ao nascer } & 3187(510,0)^{*} & 3283(590,7) & -\end{array}$

Estágio de maturação sexual

$\begin{array}{lllll}\text { I-II } & 23,8 & 46,2 & 24,0 & 46,2 \\ \text { III } & 41,4 & 25,3 & 41,0 & 25,5 \\ \text { IV -V } & 34,8 & 28,5 & 35,0 & 28,3\end{array}$

Atividade fisica (horas/dia)

$\begin{array}{lllll}\text { Atividade física } & 1,2(0,99)^{*} & 1,9(1,33) & 1,3(1,12)^{*} & 2,1(1,40) \\ \text { Sedentarismo } & 4,6(2,32) & 4,8(2,62) & 4,7(2,51) & 5,0(2,80)\end{array}$

Consumo alimentar

VET da dieta (kcal) $\quad 1620,3(405,76) \quad 1685,9(350,99)$

Lipidios $(\mathrm{g}) \quad 59,2(20,14) \quad 62,5(16,96)$

Variáveis maternas

\begin{tabular}{lcccc} 
Escolaridade (anos) & $9,1(2,90)$ & $9,5(2,57)$ & - & - \\
IMC $\left(\mathrm{kg} / \mathrm{m}^{2}\right)$ & $24,6(3,47)$ & $24,8(3,70)$ & - & - \\
Sobrepeso $(\%)$ & 38,4 & 40,3 & - & - \\
Obesidade $(\%)$ & 7,8 & 8,0 & - & - \\
\hline
\end{tabular}

${ }^{\star} p<=0,05$

Comparando-se ambos os sexos, verificou-se diferença, considerando a primeira coleta, para atividade física e peso ao nascer $(p<0,05)$. $O$ peso ao nascer para crianças e adolescentes do sexo masculino foi mais elevado quando comparado ao feminino. Para a terceira coleta, observou-se diferença estatisticamente significativa para atividade física. Meninos praticavam maior número de horas diárias de atividade física em relação às meninas (Tabela 2). 
A comparação entre as duas coletas revelou diferença estatisticamente significativa para idade, atividade física e sedentarismo $(p<0,05)$.

\subsection{Distribuição do IMC e gordura corporal}

A Tabela 3 mostra os valores das variáveis dependentes nas análises transversal e longitudinal, considerando as variáveis independentes utilizadas nas análises estatísticas.

Tabela 3 - Distribuição das variáveis dependentes - média (desvio-padrão) segundo variáveis independentes.

\begin{tabular}{|c|c|c|c|c|c|c|}
\hline \multirow{3}{*}{ Estratos } & \multicolumn{3}{|c|}{$1^{a}$ coleta } & \multicolumn{3}{|c|}{$3^{\mathrm{a}}-1^{\mathrm{a}}$ coleta $(\Delta)$} \\
\hline & \multirow{2}{*}{$\begin{array}{l}\mathrm{IMC} \\
\mathrm{kg} / \mathrm{m}^{2}\end{array}$} & \multicolumn{2}{|c|}{ Gordura corporal } & \multirow{2}{*}{$\begin{array}{l}\text { IMC } \\
\mathrm{kg} / \mathrm{m}^{2}\end{array}$} & \multicolumn{2}{|c|}{ Gordura corporal } \\
\hline & & $\mathrm{kg}$ & $\%$ & & $\mathrm{~kg}$ & $\%$ \\
\hline \multicolumn{7}{|l|}{ Sexo } \\
\hline Masculino & $20,4(4,40)$ & $9,8(6,01)^{\star}$ & $18,7(6,68)^{\star}$ & $0,4(0,72)$ & $3,1(2,07)^{\star}$ & $4,3(0,84)^{*}$ \\
\hline Feminino & $20,6(3,84)$ & $10,9(5,48)$ & $21,4(6,10)$ & $0,4(0,84)$ & $2,1(1,61)$ & $2,6(2,58)$ \\
\hline \multicolumn{7}{|l|}{ Idade (anos) } \\
\hline$<10$ & $19,5(3,54)^{\star}$ & $7,7(3,93)^{\star}$ & $20,3(6,12)$ & $0,4(0,97)$ & $1,4(1,58)^{*}$ & $1,8(3,73)$ \\
\hline $10 \vdash 11$ & $20,8(5,07)$ & $10,7(6,35)$ & $22,7(7,35)$ & $0,7(0,87)$ & $3,1(1,94)$ & $3,8(2,78)$ \\
\hline $11 \vdash 12$ & $19,4(3,66)$ & $9,0(4,79)$ & $19,6(6,23)$ & $0,5(0,90)$ & $2,1(1,84)$ & $2,6(3,13)$ \\
\hline $12 \longmapsto 13$ & $20,3(4,45)$ & $10,4(6,21)$ & $20,3(6,65)$ & $0,4(0,86)$ & $2,5(1,78)$ & $3,4(2,96)$ \\
\hline $13 \vdash 14$ & $20,7(3,59)$ & $11,0(5,78)$ & $20,0(6,28)$ & $0,3(0,60)$ & $2,7(1,59)$ & $3,6(2,50)$ \\
\hline $14 \vdash 15$ & $21,3(3,85)$ & $11,6(5,76)$ & $20,2(6,26)$ & $0,5(0,59)$ & $3,1(1,96)$ & $3,9(2,80)$ \\
\hline 15 & $21,4(3,43)$ & $11,7(5,98)$ & $19,5(6,29)$ & $0,3(0,82)$ & $2,7(2,49)$ & $3,4(3,03)$ \\
\hline$\geq 16$ & $22,3(3,32)$ & $13,5(4,92)$ & $22,3(5,35)$ & $0,4(0,69)$ & $2,9(2,31)$ & $3,5(2,23)$ \\
\hline \multicolumn{7}{|l|}{ EMS } \\
\hline $1-11$ & $19,2(3,82)^{\star}$ & $8,6(4,85)^{*}$ & $19,6(6,49)$ & $0,6(0,57)$ & $2,1(1,81)^{*}$ & $2,6(3,12)^{\star}$ \\
\hline III & $20,6(4,12)$ & $10,6(5,97)$ & $19,8(6,17)$ & $0,4(0,84)$ & $2,6(1,97)$ & $3,5(3,20)$ \\
\hline IV $-V$ & $21,7(3,53)$ & $12,4(5,63)$ & $21,4(6,31)$ & $0,4(0,68)$ & $2,7(1,84)$ & $3,5(2,62)$ \\
\hline \multicolumn{7}{|c|}{ Peso ao nascer } \\
\hline$\leq 2500 \mathrm{~g}$ & $19,9(4,32)$ & $10,3(6,01)$ & $20,1(6,02)$ & $0,6(0,71)$ & $2,1(1,85)^{*}$ & $2,5(2,88)^{*}$ \\
\hline $2500-3500$ & $20,2(3,65)$ & $9,99(5,17)$ & $20,1(6,14)$ & $0,5(0,77)$ & $2,4(1,78)$ & $3,1(2,92)$ \\
\hline$\geq 3500$ & $21,0(4,13)$ & $11,2(5,83)$ & $20,7(6,62)$ & $0,4(1,02)$ & $2,8(2,20)$ & $3,5(3,15)$ \\
\hline
\end{tabular}


Tabela 3 - continuação

\begin{tabular}{|c|c|c|c|c|c|c|}
\hline \multirow{3}{*}{ Estratos } & \multicolumn{3}{|c|}{1 coleta } & \multicolumn{3}{|c|}{$3^{a}-1^{2}$ coleta $(\Delta)$} \\
\hline & \multirow{2}{*}{$\frac{\mathrm{IMC}}{\mathrm{kg} / \mathrm{m}^{2}}$} & \multicolumn{2}{|c|}{ Gordura corporal } & \multirow{2}{*}{$\begin{array}{l}\text { IMC } \\
\mathrm{kg} / \mathrm{m}^{2}\end{array}$} & \multicolumn{2}{|c|}{ Gordura corporal } \\
\hline & & $\mathrm{kg}$ & $\%$ & & $\mathrm{~kg}$ & $\%$ \\
\hline \multicolumn{7}{|c|}{ Atividade fisica } \\
\hline Não pratica & $20,7(4,28)$ & $10,9(5,60)$ & $20,9(6,16)^{\star}$ & $0,3(0,94)$ & $2,3(1,78)^{\star}$ & $2,9(2,71)$ \\
\hline 1 ou 2 h/dia & $20,2(3,95)$ & $10,3(5,57)$ & $20,3(6,31)$ & $0,5(0,80)$ & $2,4(1,81)$ & $3,1(2,94)$ \\
\hline 3 ou + h/dia & $20,3(3,31)$ & $9,7(5,25)$ & $18,5(6,34)$ & $0,6(0,87)$ & $3,1(2,58)$ & $3,9(3,64)$ \\
\hline \multicolumn{7}{|c|}{ Sedentarismo } \\
\hline$\leq 2 \mathrm{~h} / \mathrm{dia}$ & $20,0(3,52)$ & $9,79(4,52)$ & $20,0(6,04)$ & $0,4(0,81)$ & $2,3(1,89)$ & $3,1(2,98)$ \\
\hline $2-4 \mathrm{~h} / \mathrm{dia}$ & $20,4(4,19)$ & $10,7(5,90)$ & $20,7(6,37)$ & $0,5(0,91)$ & $2,4(1,94)$ & $3,0(2,95)$ \\
\hline$\geq 4 \mathrm{~h} / \mathrm{dia}$ & $20,6(3,85)$ & $10,2(5,53)$ & $19,6(6,38)$ & $0,5(0,76)$ & $2,6(1,94)$ & $3,4(3,09)$ \\
\hline \multicolumn{7}{|c|}{ Renda per capita } \\
\hline$\leq 1 \mathrm{SM}^{1}$ & $19,9(4,12)^{\star}$ & $9,8(5,64)^{\star}$ & $19,6(6,17)^{\star}$ & $0,4(0,83)$ & $2,3(1,75)$ & $3,0(3,05)$ \\
\hline $1-3 S M$ & $20,1(3,52)$ & $10,0(5,03)$ & $19,8(6,10)$ & $0,5(0,84)$ & $2,5(1,89)$ & $3,2(2,88)$ \\
\hline$\geq 3 \mathrm{SM}$ & $21,6(4,19)$ & $11,8(5,92)$ & $22,1(6,58)$ & $0,4(0,91)$ & $2,7(2,25)$ & $3,3(3,10)$ \\
\hline \multicolumn{7}{|c|}{ Escolaridade materna } \\
\hline$\leq 6$ anos & $19,5(3,83)^{*}$ & $9,0(4,61)^{\star}$ & $18,6(5,54)^{*}$ & $0,5(0,86)$ & $2,4(1,85)$ & $3,2(2,98)$ \\
\hline $6-11$ anos & $20,2(3,75)$ & $10,3(5,47)$ & $20,1(5,94)$ & $0,5(0,88)$ & $2,4(1,74)$ & $3,1(2,78)$ \\
\hline$\geq 11$ anos & $20,8(4,04)$ & $11,0(5,82)$ & $21,0(6,61)$ & $0,4(0,84)$ & $2,5(2,03)$ & $3,1(3,08)$ \\
\hline \multicolumn{7}{|c|}{ IMC materno } \\
\hline$<25$ & $20,0(3,67)^{\star}$ & $9,9(5,15)^{*}$ & $19,7(5,97)^{\star}$ & $0,4(0,83)$ & $2,4(1,92)$ & $3,1(2,95)$ \\
\hline $25 \mid-30$ & $20,4(3,88)$ & $10,4(5,57)$ & $20,3(6,53)$ & $0,6(0,84)$ & $2,6(1,95)$ & $3,2(3,07)$ \\
\hline$\geq 30$ & $22,7(5,21)$ & $13,6(6,79)$ & $23,5(6,86)$ & $0,3(0,96)$ & $2,6(1,93)$ & $3,0(3,06)$ \\
\hline \multicolumn{7}{|c|}{ VET da dieta ${ }^{2}$} \\
\hline $1^{\circ}$ tercil & $19,9(4,14)^{*}$ & $9,6(5,60)^{*}$ & $19,3(5,98)$ & $0,5(0,91)$ & $2,4(2,08)$ & $3,1(3,13)$ \\
\hline $2^{\circ}$ tercil & $20,5(3,91)$ & $10,7(5,73)$ & $20,9(6,43)$ & $0,4(0,88)$ & $2,3(1,74)$ & $2,9(2,66)$ \\
\hline $3^{\circ}$ tercil & $21,1(4,03)$ & $11,3(5,68)$ & $21,1(6,76)$ & $0,4(0,81)$ & $2,5(2,08)$ & $3,2(3,32)$ \\
\hline \multicolumn{7}{|l|}{ Lipidio $^{3}$} \\
\hline $1^{\circ}$ tercil & $20,3(4,25)$ & $10,5(5,71)$ & $20,5(6,11)$ & $0,4(0,94)$ & $2,2(1,80)$ & $2,7(2,81)$ \\
\hline $2^{\circ}$ tercil & $20,2(3,83)$ & $10,2(5,70)$ & $19,9(6,47)$ & $0,5(0,75)$ & $2,5(1,89)$ & $3,3(2,99)$ \\
\hline $3^{\circ}$ tercil & $20,9(4,05)$ & $10,9(5,69)$ & $20,8(6,72)$ & $0,5(0,89)$ & $2,6(2,20)$ & $3,2(3,30)$ \\
\hline
\end{tabular}

${ }^{\top} \mathrm{SM}=$ salário mínimo

${ }^{2}$ VET da dieta: $1^{\circ}$ tercil: $\leq 1478 \mathrm{kcal} ; 2^{\circ}$ tercil: entre 1479 e $1751 \mathrm{kcal}$ e $3^{\circ}$ tercil: $\geq 1753 \mathrm{kcal}$

${ }^{3}$ Lipidio: $1^{\circ}$ tercil: $\leq 53 \mathrm{~g} ; 2^{\circ}$ tercil: entre 54 e $74 \mathrm{~g} \mathrm{e} 3^{\circ}$ tercil: $\geq 75 \mathrm{~g}$

${ }^{\star} p<=0,05$ 
Observou-se diferença estatisticamente significante para renda per capita, escolaridade e IMC materno para os valores da primeira coleta das três variáveis dependentes estudadas. Para o IMC, houve também diferença para idade, EMS e VET da dieta $(p<0,05)$. Para a massa adiposa $(\mathrm{kg})$, houve diferença para sexo, idade, EMS e VET da dieta $(p<0,05)$. As diferenças observadas para gordura corporal (\%) foram significativas para atividade física e sexo (Tabela 3). Foi observada relação positiva entre as variáveis dependentes e EMS, renda per capita, escolaridade materna, IMC materno e VET da dieta. Relação inversa foi encontrada entre atividade física e porcentagem de gordura corporal.

A análise das médias referentes às diferenças entre a terceira e primeira coletas, mostra que, considerando o IMC, não houve diferença estatisticamente significante para nenhuma das variáveis. A quantidade absoluta de massa adiposa apresentou diferença para sexo, idade, EMS, peso ao nascer e atividade física $(p<0,05)$, enquanto, para quantidade relativa, verificou-se diferença para sexo, EMS e peso ao nascer (Tabela 3). Foi verificada relação positiva entre variação temporal de gordura corporal ( $\mathrm{kg} \mathrm{e} \mathrm{\% )} \mathrm{e} \mathrm{EMS} \mathrm{e} \mathrm{peso} \mathrm{ao} \mathrm{nascer.} \mathrm{Tal}$ relação foi observada, também, entre variação temporal da quantidade absoluta de massa adiposa e atividade física.

A Tabela 4 apresenta as prevalências de sobrepeso e obesidade segundo as diferentes variáveis independentes estudadas. 
Tabela 4 - Distribuição da prevalência de sobrepeso e obesidade, segundo variáveis independentes.

\begin{tabular}{|c|c|c|c|c|}
\hline \multirow[t]{2}{*}{ Estratos } & \multicolumn{2}{|c|}{ Sobrepeso } & \multicolumn{2}{|c|}{ Obesidade } \\
\hline & $n$ & $\%$ & $n$ & $\%$ \\
\hline \multicolumn{5}{|l|}{ Sexo } \\
\hline Masculino & 48 & 28,7 & 21 & 12,6 \\
\hline Feminino & 83 & 26,3 & 23 & 7,3 \\
\hline \multicolumn{5}{|l|}{ Idade (anos) } \\
\hline$<10$ & 12 & 44,4 & $05^{\star}$ & 18,6 \\
\hline $10 \vdash 11$ & 11 & 39,3 & 07 & 25,0 \\
\hline $11 \vdash 12$ & 52 & 31,7 & 15 & 9,2 \\
\hline $12 \vdash 13$ & 43 & 27,2 & 20 & 12,7 \\
\hline $13 \vdash 14$ & 36 & 25,0 & 08 & 5,6 \\
\hline $14 \vdash 15$ & 16 & 22,5 & 06 & 8,5 \\
\hline $15 \longmapsto 16$ & 09 & 26,5 & 01 & 2,9 \\
\hline$\geq 16$ & 05 & 14,7 & 02 & 5,9 \\
\hline \multicolumn{5}{|l|}{ EMS } \\
\hline I- II & 53 & 29,3 & $23^{*}$ & 12,7 \\
\hline III & 44 & 28,6 & 20 & 12,9 \\
\hline IV $-V$ & 87 & 26,8 & 21 & 6,5 \\
\hline \multicolumn{5}{|c|}{ Peso ao nascer } \\
\hline$\leq 2500 \mathrm{~g}$ & 10 & 17,9 & 05 & 8,9 \\
\hline $2500-3500$ & 69 & 25,1 & 20 & 7,3 \\
\hline$\geq 3500$ & 53 & 33,8 & 17 & 10,8 \\
\hline \multicolumn{5}{|c|}{ Atividade fisica } \\
\hline Não pratica & 35 & 28,7 & 12 & 9,8 \\
\hline 1 ou 2 h/dia & 82 & 27,5 & 29 & 9,7 \\
\hline $3 \mathrm{ou}+\mathrm{h} / \mathrm{dia}$ & 14 & 22,2 & 03 & 4,8 \\
\hline \multicolumn{5}{|l|}{ Sedentarismo } \\
\hline$\leq 2 \mathrm{~h} / \mathrm{dia}$ & 22 & 21,8 & 06 & 5,9 \\
\hline $2-4 \mathrm{~h} / \mathrm{dia}$ & 72 & 29,3 & 25 & 10,2 \\
\hline$\geq 4 \mathrm{~h} / \mathrm{dia}$ & 37 & 27,2 & 13 & 9,6 \\
\hline \multicolumn{5}{|c|}{ Renda per capita } \\
\hline$\leq 1 S M^{1}$ & 41 & 23,2 & 15 & 8,5 \\
\hline $1-3 S M$ & 52 & 26,9 & 15 & 7,8 \\
\hline$\geq 3 \mathrm{SM}$ & 38 & 33,6 & 14 & 12,4 \\
\hline
\end{tabular}


Tabela 4 - continuação

\begin{tabular}{lcccc}
\hline Estratos & \multicolumn{2}{c}{ Sobrepeso } & \multicolumn{2}{c}{ Obesidade } \\
\cline { 2 - 5 } & $n$ & $\%$ & $n$ & $\%$ \\
\hline Escolaridade materna & & & 07 & 5,9 \\
$\leq 6$ anos & 24 & 20,3 & 06 & 6,7 \\
$6-11$ anos & 21 & 23,6 & 31 & 11,2 \\
$\geq 11$ anos & 86 & 31,2 & & \\
IMC materno & & & $19^{*}$ & 6,6 \\
$<25$ & $73^{*}$ & 25,2 & 13 & 8,7 \\
$25 \mid-30$ & 37 & 25,8 & 12 & 27,3 \\
$\geq 30$ & 21 & 47,7 & & \\
VET da dieta $^{2}$ & & & 13 & 8,51 \\
$1^{\circ}$ tercil & $30^{*}$ & 21,28 & 12 & 8,86 \\
$2^{\circ}$ tercil & 41 & 29,29 & 18 & 12,86 \\
$3^{\circ}$ tercil & 50 & 35,71 & & 11,35 \\
Lipídio $^{3}$ & & & 16 & 5,71 \\
$1^{\circ}$ tercil & 36 & 25,53 & 08 & 12,14 \\
$2^{\circ}$ tercil & 37 & 26,43 & 17 & \\
$3^{\circ}$ tercil & 48 & 34,29 & & \\
\hline
\end{tabular}

SM = salário mínimo

${ }^{2}$ VET da dieta: $1^{\circ}$ tercil: $\leq 1478 \mathrm{kcal} ; 2^{\circ}$ tercil: entre 1479 e $1751 \mathrm{kcal}$ e $3^{\circ}$ tercil: $\geq 1753 \mathrm{kcal}$

${ }^{3}$ Lipídio: $1^{\circ}$ tercil: $\leq 53 \mathrm{~g} ; 2^{\circ}$ tercil: entre 54 e $74 \mathrm{~g} \mathrm{e} 3^{\circ}$ tercil: $\geq 75 \mathrm{~g}$

* $p<=0,05$

Conforme observado na Tabela 4, houve associação entre sobrepeso e IMC materno e tercil de VET da dieta $(p<0,05)$. Enquanto que para obesidade, as associações estatisticamente significantes incluem idade, estágio de maturação sexual, e IMC materno. Foi observada relação diretamente proporcional entre sobrepeso/obesidade e IMC materno. Encontrou-se mesma relação entre sobrepeso e VET da dieta. 


\subsection{Análise transversal}

A análise transversal apresenta os resultados dos modelos de regressão, utilizando como variáveis dependentes os valores transversais, da primeira coleta, de IMC e de gordura corporal (kg e \%).

\subsubsection{Análise univariada}

Inicialmente, foram verificadas as correlações entre as variáveis dependentes e independentes, segundo sexo, apresentadas na Tabela 5.

Tabela 5 - Coeficientes de correlação entre as variáveis dependentes e independentes segundo sexo.

\begin{tabular}{|c|c|c|c|c|c|c|}
\hline \multirow[t]{3}{*}{ Variáveis indepen } & \multicolumn{6}{|c|}{ Variáveis dependentes - valor transversal } \\
\hline & \multicolumn{2}{|c|}{$\mathrm{IMC}-\mathrm{kg} / \mathrm{m}^{2}$} & \multicolumn{2}{|c|}{ Gordura corporal - kg } & \multicolumn{2}{|c|}{ Gordura corporal - \% } \\
\hline & P & $\delta$ & T & \% & क & उ \\
\hline Idade & $0,21^{\star}$ & 0,16 & $0,33^{\star}$ & $0,21^{\star}$ & $0,19^{*}$ & $-0,14^{\star}$ \\
\hline Peso ao nascer & $0,16^{*}$ & 0,10 & $0,13^{*}$ & 0,03 & $0,09^{*}$ & 0,02 \\
\hline Atividade física & 0,02 & $-0,03$ & 0,02 & $-0,06$ & 0,01 & $-0,16$ \\
\hline Sedentarismo & 0,11 & $-0,08$ & 0,08 & $-0,11$ & 0,04 & $-0,14$ \\
\hline Renda per capita & $0,13^{*}$ & $0,28^{\star}$ & $0,15^{\star}$ & $0,22^{\star}$ & $0,17^{*}$ & $0,13^{\star}$ \\
\hline Escolaridade mãe & $0,12^{\star}$ & 0,09 & $0,13^{*}$ & 0,07 & $0,15^{\star}$ & 0,05 \\
\hline IMC materno & $0,17^{*}$ & 0,16 & $0,19^{*}$ & $0,19^{*}$ & $0,17^{\star}$ & $0,16^{*}$ \\
\hline VET da dieta & 0,05 & 0,12 & 0,11 & 0,07 & 0,09 & 0,02 \\
\hline Lipidios & 0,02 & 0,08 & 0,06 & 0,01 & 0,04 & $-0,05$ \\
\hline
\end{tabular}

${ }^{\star} p<0,05$

O coeficiente de correlação máximo obtido foi 0,33 . As variáveis idade, renda per capita e IMC materno apresentaram altas correlações para ambos os sexos e todas as variáveis dependentes, enquanto o peso ao nascer apresentou maior correlação para o sexo feminino, quando comparado ao masculino. Renda per capita apresentou maiores coeficientes de correlação quando comparada à escolaridade materna. 
Para o sexo feminino, foi observada correlação positiva entre todas as variáveis estudadas. Para o masculino, verificou-se correlação negativa para atividade física e sedentarismo. Em relação à porcentagem de gordura corporal, registrouse correlação negativa para idade e lipídios consumidos, entre os meninos

Considerando o IMC e quantidade absoluta de gordura corporal, os coeficientes de correlação mais elevados foram idade das crianças e adolescentes, IMC materno e renda per capita, para ambos os sexos. Para o sexo feminino, observou-se também correlação com peso ao nascer $(0,16)$. Para a quantidade relativa de gordura corporal, as maiores correlações, para o sexo masculino foram com a idade, atividade física, sedentarismo, IMC materno e renda per capita. Para as meninas, foram com IMC materno, idade e renda per capita.

Foram encontrados coeficientes de correlação de Pearson de 0,91, sendo 0,92 para meninas e 0,91 para meninos, entre os valores de IMC e de gordura corporal $(\mathrm{kg})$ determinada por BIA.

\subsubsection{Análise linear multivariada}

Baseando-se na matriz de correlação entre as variáveis dependentes e independentes foram criados modelos constituídos pelas variáveis significativas na predição do IMC e gordura corporal ( $\mathrm{kg} \mathrm{e} \mathrm{\% ).} \mathrm{Todos} \mathrm{os} \mathrm{modelos} \mathrm{foram} \mathrm{criados}$ separadamente, para meninas e meninos, devido ao fato da variável sexo ser modificadora de efeito.

As análises de regressão foram feitas seguindo a técnica de forward. As variáveis foram ordenadas segundo coeficiente de correlação para entrada no modelo. A significância estatística foi o critério de permanência $(p<0,05)$ e saída $(p>0,05)$ das variáveis no modelo. Foi realizada análise dos resíduos e os erros foram aleatórios (HAIR e col. 1998). 
A Tabela 6 apresenta os resultados das análises transversais para o sexo feminino.

Tabela 6 - Análise linear multivariada para o sexo feminino $(n=290)$, segundo valor transversal das variáveis dependentes.

Coeficiente (erro padrão)

Intervalo de confiança do coeficiente

\begin{tabular}{lccc}
\cline { 2 - 4 } & IMC $\left(\mathbf{k g} / \mathbf{m}^{2}\right)$ & Gordura $\mathbf{~ g g}$ & Gordura \% \\
\hline Intercepto & $-3,472^{\star \star}(0,563)$ & $0,027(0,295)$ & $2,012^{\star \star}(0,189)$ \\
Variável independente & $(-4,580--2,365)$ & $(-0,553-0,608)$ & $(1,642-2,381)$ \\
Idade & $0,008^{\star \star}(0,002)$ & $0,007^{\star \star}(0,001)$ & $0,002^{\star \star}(0,001)$ \\
& $(0,004-0,012)$ & $(0,004-0,009)$ & $(0,001-0,004)$ \\
Peso ao nascer & $0,001^{\star \star}(0,0001)$ & $0,001^{\star \star}(0,001)$ & $0,001^{\star}(0,001)$ \\
& $(0,0001-0,0004)$ & $(0,0001-0,0002)$ & $(0,0001-0,0002)$ \\
Renda per capita & $0,070^{\star}(0,028)$ & $0,040^{\star \star}(0,015)$ & $0,029^{\star \star}(0,009)$ \\
& $(0,015-0,125)$ & $(0,011-0,068)$ & $(0,011-0,048)$ \\
IMC materno & $0,047^{\star \star}(0,014)$ & $0,026^{\star \star}(0,007)$ & $0,015^{\star \star}(0,005)$ \\
& $(0,020-0,074)$ & $(0,012-0,040)$ & $(0,006-0,024)$ \\
$R^{2}$ ajustado & 0,11 & 0,17 & 0,11 \\
\hline
\end{tabular}

${ }^{\star} p<0,05,{ }^{\star \star} p<0,01$

Em análise multivariada, as variáveis significativas em todos os modelos propostos foram idade, renda per capita, IMC materno e peso ao nascer. Observou-se relação positiva entre tais variáveis e os valores transversais de IMC e gordura corporal ( $\mathrm{kg} \mathrm{e} \mathrm{\% ).}$ 
Tabela 7 - Análise linear multivariada para o sexo masculino $(n=163)$, segundo valor transversal das variáveis dependentes.

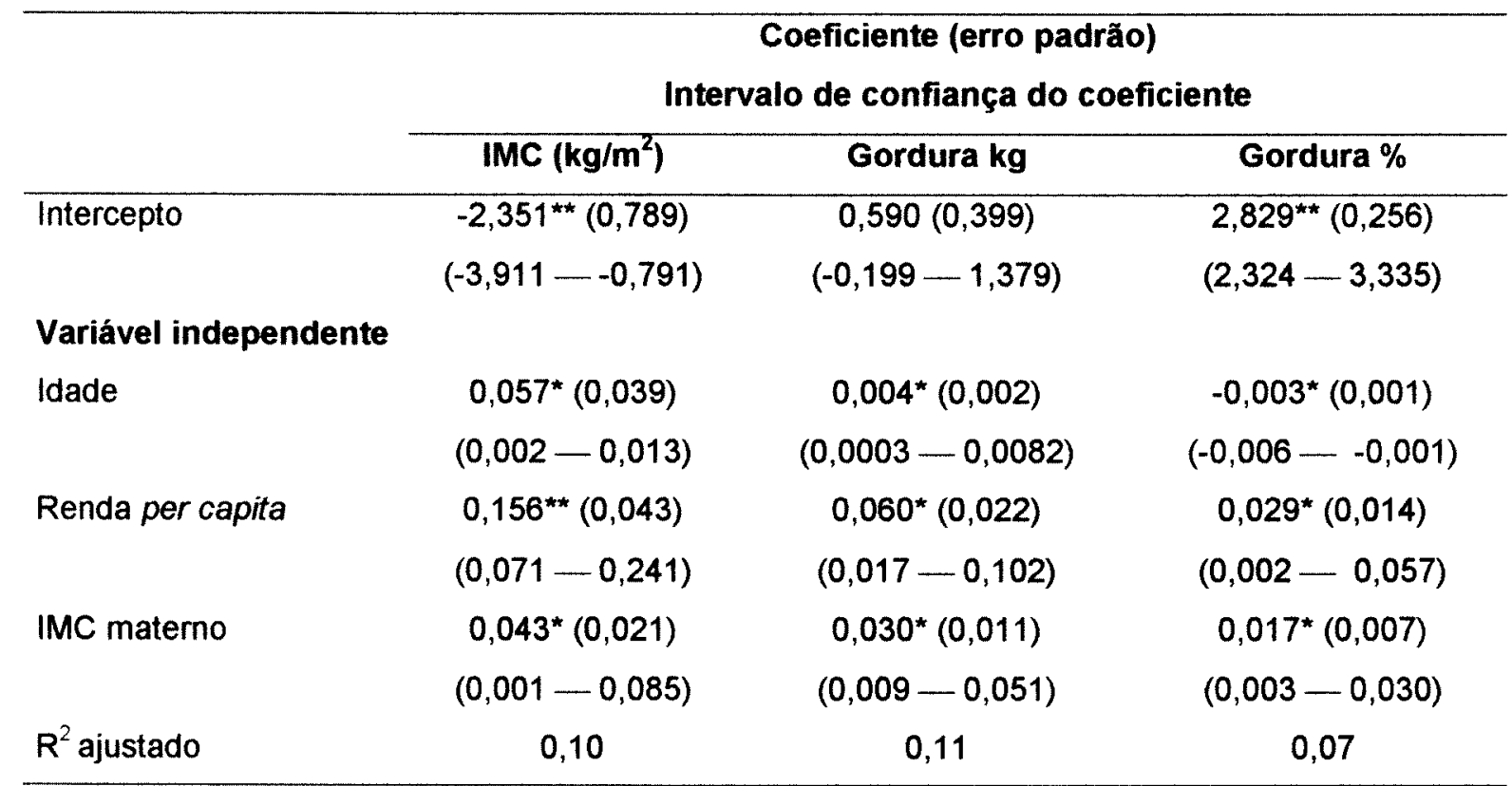

${ }^{\star} p<0,05 ;{ }^{\star \star} p<0,01$

Observando- se a Tabela 7, nota-se que, para o sexo masculino, as variáveis idade, renda per capita e IMC materno estão associadas a todas as variáveis estudadas. Diferentemente do sexo feminino, o peso ao nascer não constituiu variável significativa no modelo. Observou-se relação positiva entre as variáveis e os valores transversais de IMC e gordura corporal ( $\mathrm{kg}$ e \%), com exceção da idade, que apresentou relação inversa com a quantidade relativa de gordura corporal.

\subsubsection{Análise logística}

As tabelas 8 e 9 apresentam os preditores para sobrepeso e obesidade dos indivíduos estudados, com diagnóstico baseado nos pontos de corte para valores de IMC por sexo e idade, propostos para uso internacional (COLE e col. 2000).

Para análise logística, as variáveis independentes foram categorizadas conforme apresentado na Tabela 4. Realizou-se teste de associação entre as variáveis dependentes e independentes e estas foram ordenadas segundo significância 
estatística para entrada no modelo. O critério de permanência foi a significância $(p<0,05)$ e os modelos foram ajustados por sexo (HAIR e col. 1998).

Tabela 8 - Preditores de sobrepeso nos indivíduos estudados.

\begin{tabular}{lccc}
\hline \multicolumn{1}{c}{ Preditores $^{\star}$} & Subgrupo $\mathbf{n}(\%)$ & OR. & IC 95\% \\
\hline $\begin{array}{l}\text { Obesidade materna } \\
\text { Não }\end{array}$ & $386(91,7)$ & 1 & Referência \\
Sim & $35(8,3)$ & 3,09 & $(1,50-6,37)$ \\
Peso ao nascer & & & \\
entre 2500 e 3500g & $234(55,6)$ & 1 & Referência \\
$\leq 2500 \mathrm{~g}$ & $47(11,2)$ & 0,72 & $(0,32-1,58)$ \\
$\geq 3500 \mathrm{~g}$ & $140(33,3)$ & 1,71 & $(1,06-2,75)$ \\
\hline
\end{tabular}

*Ajustados por sexo

Verificou-se que obesidade materna e peso ao nascer superior a $3500 \mathrm{~g}$ foram fatores de risco para a presença de sobrepeso. Detectou-se, ainda, que indivíduos filhos de mães obesas têm chance aproximadamente duas vezes maior de apresentarem sobrepeso quando comparados aos filhos de mães eutróficas (Tabela 8).

Tabela 9 - Preditores de obesidade nos indivíduos estudados.

\begin{tabular}{lccc}
\hline \multicolumn{1}{c}{ Preditores* $^{*}$} & Subgrupo $\mathbf{n}(\%)$ & OR. & IC 95\% \\
\hline Obesidade materna & $386(91,7)$ & 1 & Referência \\
Não & $35(8,3)$ & 5,20 & $(2,26-10,01)$ \\
Sim & & & \\
\hline
\end{tabular}

*Ajustados por sexo

A Tabela 9 mostra que a variável obesidade materna é a principal preditora para a obesidade das crianças e adolescentes estudados. Indivíduos, filhos de mães obesas apresentaram chance de obesidade 4,2 vezes maior em relação aos filhos de mães eutróficas. 


\subsection{Análise longitudinal}

Realizaram-se análises longitudinais considerando variáveis dependentes as variações temporais de IMC e gordura corporal ( $\mathrm{kg}$ e \%).

\subsubsection{Análise univariada}

As correlações entre as variáveis dependentes e independentes, segundo sexo, apresentadas na Tabela 10, indicam maiores coeficientes de correlação para os valores iniciais, obtidos na primeira coleta.

Tabela 10 - Coeficientes de correlação entre as variáveis dependentes e independentes segundo sexo.

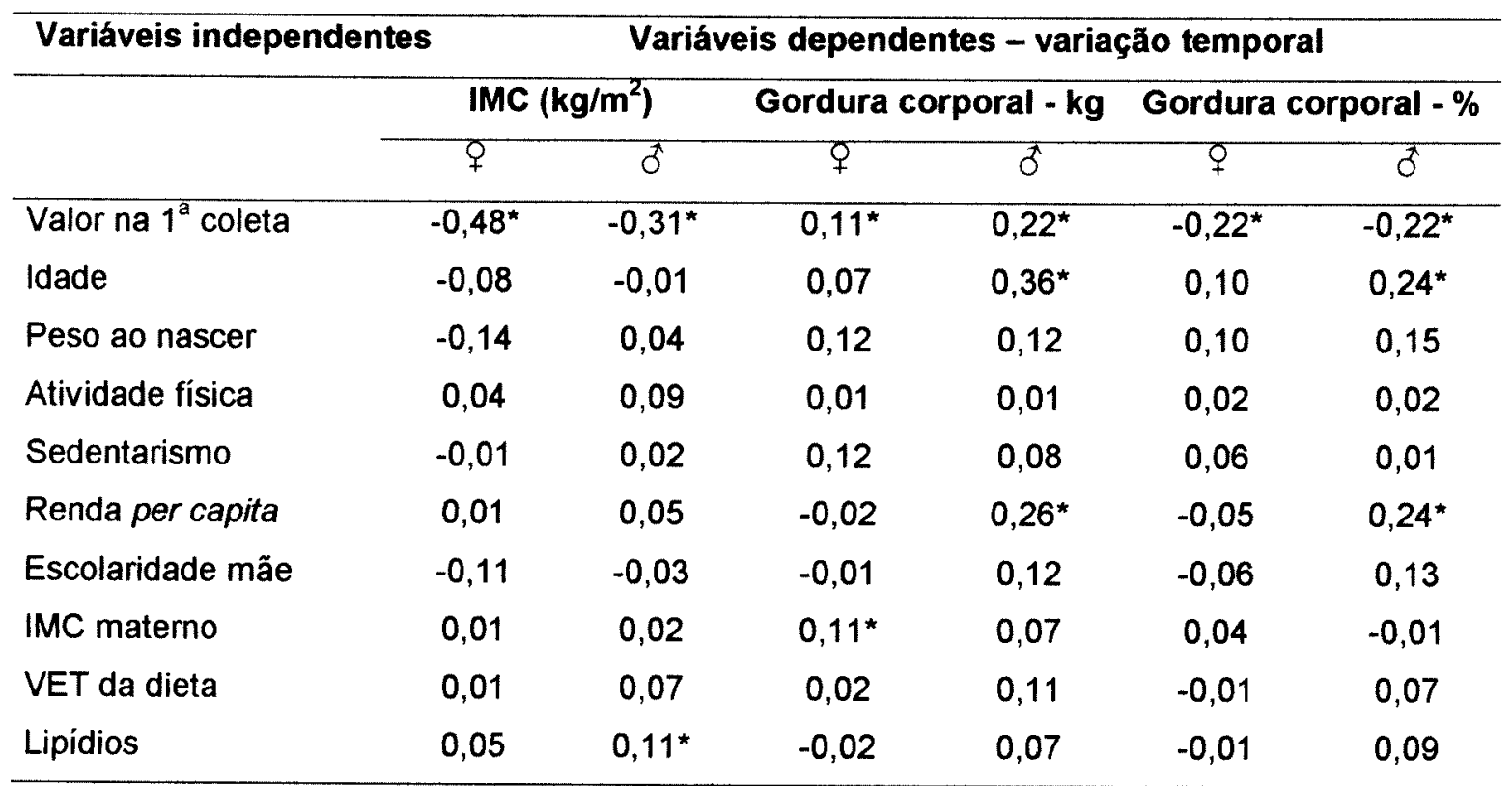

${ }^{*} p<0,05$

Para o IMC, os coeficientes de correlação variaram entre $-0,48$ e 0,09 . Com relação à quantidade absoluta de gordura corporal, observaram-se correlações superiores para o sexo masculino, para valor da $1^{\text {a }}$ coleta, idade, renda per capita, escolaridade materna, VET da dieta e lipídios consumidos, quando comparado ao feminino. Quanto à porcentagem de gordura corporal, os coeficientes de correlação foram iguais para valor inicial e atividade física, em ambos os sexos. Meninos apresentaram correlações superiores às meninas, para 
idade, peso ao nascer, escolaridade materna, renda per capita, VET da dieta e lipídios consumidos.

\subsubsection{Análise linear multivariada}

Com base nos coeficientes de correlação entre as variáveis dependentes e independentes desenvolveram-se modelos contendo as variáveis independentes significativas na predição da variação temporal do IMC e gordura corporal (kg e $\%)$.

Tabela 11 - Análise linear multivariada para o sexo feminino $(n=290)$, segundo variação temporal das variáveis dependentes.

Coeficiente (erro padrão)

Intervalo de confiança do coeficiente

\begin{tabular}{lccc}
\cline { 2 - 4 } & IMC $\left(\mathbf{k g} / \mathbf{m}^{2}\right)$ & Gordura $\mathbf{~ k g}$ & Gordura \% \\
\hline Intercepto & $2,295^{\star \star}(0,199)$ & $1,639^{\star \star}(0,203)$ & $4,398^{\star \star}(0,530)$ \\
& $(1,902-2,687)$ & $(1,239-2,038)$ & $(3,356-5,440)$ \\
Variável independente & & & \\
Valor na $1^{\text {a }}$ coleta & $-0,088^{\star \star}(0,010)$ & $0,041^{\star}(0,017)$ & $-0,086^{\star \star}(0,024)$ \\
& $(-0,107-0,069)$ & $(0,008-0,074)$ & $(-0,133--0,039)$ \\
$\mathrm{R}^{2}$ ajustado & 0,22 & 0,05 & 0,04 \\
\hline
\end{tabular}

${ }^{\star} p<0,05,{ }^{\star \star *} p<0,01$

Para meninas, encontrou-se associação significativa entre o valor da primeira coleta e todas as variáveis dependentes estudadas. Observou-se relação inversa entre o valor inicial e as alterações temporais de IMC e porcentagem de gordura corporal, e relação positiva entre o valor inicial e a variação temporal de massa adiposa (\%). Os modelos apresentaram $R^{2}$ ajustado de 0,22; 0,05 e 0,04 para variação temporal de IMC e gordura corporal em $\mathrm{kg}$ e \%, respectivamente (Tabela 11). 
Tabela 12 - Análise linear multivariada para o sexo masculino $(n=163)$, segundo variação temporal das variáveis dependentes.

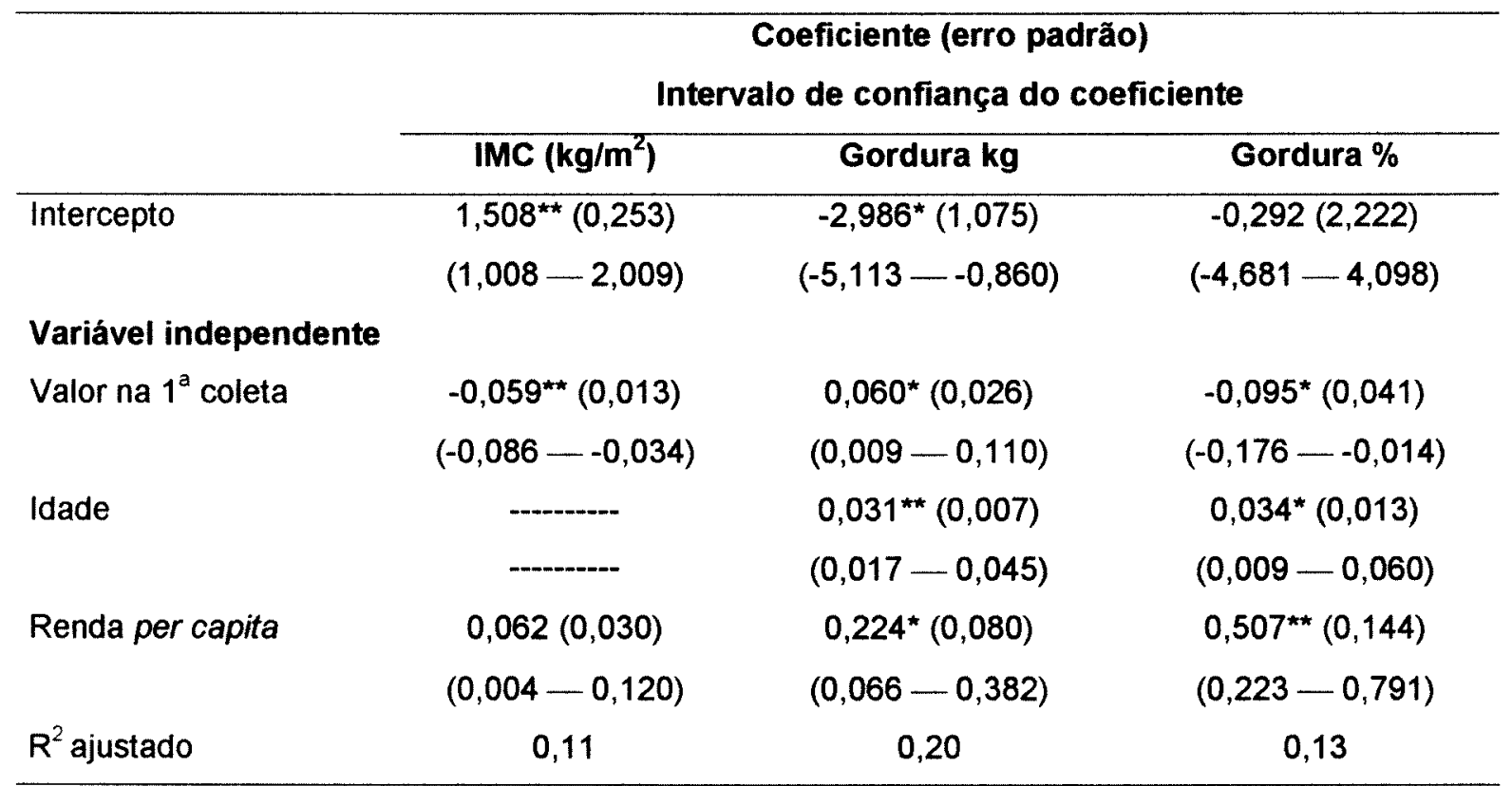

${ }^{\star} p<0,05,{ }^{\star \star} p<0,01$

A Tabela 12 mostra que o valor de IMC na primeira coleta e renda per capita associaram-se à variação temporal de IMC, para o sexo masculino $\left(R^{2}\right.$ ajustado $=$ 0,11 ). Para a quantidade de gordura corporal em $\mathrm{kg} \mathrm{e} \%$, as variáveis associadas foram valor inicial (na $1^{\mathrm{a}}$ coleta), idade e renda per capita $\left(R^{2}\right.$ ajustado $=0,20 \mathrm{e}$ 0,13 ; respectivamente).

Verificou-se relação positiva entre renda per capita e a variação temporal de todas as variáveis estudadas, mesma relação observada entre idade e gordura corporal ( $\mathrm{kg} \mathrm{e} \mathrm{\% ).} \mathrm{Igualmente} \mathrm{ao} \mathrm{sexo} \mathrm{feminino,} \mathrm{foi} \mathrm{encontrada} \mathrm{relação} \mathrm{inversa}$ entre o valor inicial e as alterações temporais de IMC e porcentagem de gordura corporal, e relação positiva entre o valor inicial e a variação temporal de massa adiposa (\%). 
DISCUSSÃO 


\section{DISCUSSÃO}

O presente trabalho teve como principal objetivo analisar os fatores associados ao sobrepeso e obesidade em indivíduos de 8 a 18 anos de idade. Para a variação temporal de IMC e gordura corporal, os valores iniciais das variáveis dependentes foram os principais fatores associados presentes nos modelos. Idade, IMC materno e renda per capita associaram-se aos valores transversais de IMC e massa adiposa, enquanto variáveis referentes ao consumo alimentar, atividade física e sedentarismo não foram significativas nas análises. Peso ao nascer associou-se positivamente ao IMC e gordura corporal, somente em meninas.

Quanto ao estado nutricional das crianças e adolescentes, a principal variável associada tanto ao sobrepeso quanto à obesidade foi a obesidade materna. Peso ao nascer acima de $3500 \mathrm{~g}$ constituiu fator de risco para sobrepeso.

A discussão deste trabalho foi estruturada em tópicos referentes a validade interna e externa dos resultados obtidos, incluindo a comparação com os achados descritos na literatura.

\subsection{Validade interna}

A discussão da validade interna dos achados deste estudo contém o delineamento e a plausibilidade das relações encontradas entre as variáveis estudadas, contemplando a qualidade dos métodos empregados na coleta das variáveis de interesse.

\subsubsection{Delineamento do estudo}

Ainda que estudos com delineamento transversal permitam verificar associações entre variáveis, impossibilitam determinar relações causais entre as mesmas. Estudos com delineamento longitudinal propiciam o entendimento sobre o curso natural do crescimento e desenvolvimento durante a infância e adolescência, 
bem como a identificação dos fatores associados às alterações do estado nutricional e indicadores de risco à saúde.

Uma das premissas necessárias para a construção de alguns modelos estatísticos diz respeito à independência entre as diferentes medidas. Entretanto, em estudos longitudinais, esta premissa não se aplica, uma vez que medidas do mesmo individuo em momentos diferentes são dependentes.

Neste estudo, optou-se por estudar a diferença entre as duas medidas (valor da terceira coleta - valor da primeira coleta), fato que elimina a dependência entre medidas nos diferentes momentos.

Os modelos dos valores transversais das variáveis dependentes apresentaram $R^{2}$ ajustados pequenos, variando entre 0,07 e 0,17 . Os modelos para as variaçōes temporais apresentaram $R^{2}$ ajustados entre 0,04 e 0,22. Estes valores indicam que as variáveis independentes estudadas explicam apenas uma parte da variabilidade observada para as variáveis dependentes.

Outro aspecto relevante aos estudos de seguimento diz respeito às perdas obtidas, que no presente estudo corresponderam a $6,6 \%$ da amostra inicial. Entretanto, ocorreu perda relacionada às informações solicitadas aos pais, observando-se perda total de $26,8 \%$, o que, possivelmente, propiciou a diminuição do poder dos testes estatísticos e a precisão da estimativa dos parâmetros.

A comparação do IMC e gordura corporal entre o grupo de indivíduos que participou do seguimento e o que foi excluido, devido aos dados incompletos, mostrou ausência de diferença estatística entre as variáveis dependentes deste estudo. 


\subsubsection{As variáveis dependentes}

\subsubsection{O IMC e o diagnóstico de sobrepeso/obesidade}

A utilização do índice de massa corporal (IMC) para o diagnóstico de sobrepeso/obesidade no presente estudo é permeada por duas questões relevantes. A primeira diz respeito ao IMC refletir ou não a quantidade de gordura corporal e a segunda aos valores dos pontos de corte que definem sobrepeso/obesidade em crianças e adolescentes.

O índice de massa corporal é amplamente utilizado na avaliação do estado nutricional em estudos populacionais. Porém, os valores de IMC não identificam os diferentes componentes corporais como massa magra e massa adiposa e consequentemente, O IMC constitui medida indireta da obesidade, patologia definida como excesso de gordura corporal (WHO 1995).

No presente estudo, foram encontrados coeficientes de correlação de Pearson de 0,91 (0,92 para meninas e 0,91 para meninos) entre os valores de IMC e de gordura corporal $(\mathrm{kg})$ determinada por BIA. Embora estes valores sejam altos, não existem achados conclusivos sobre este tema para a população adolescente.

Estudos realizados com crianças e adolescentes norte-americanos encontraram coeficientes de correlação entre IMC e gordura corporal variando entre 0,34 e 0,94 para o sexo masculino e 0,67 e 0,96 para o feminino (DANIELS e col. 1997, ELLIS e col. 1999, MAYNARD e col. 2001, MEl e col. 2002).

O elevado coeficiente de correlação entre o IMC e a gordura corporal, obtida por BIA, observado neste estudo, é de grande importância para estudos epidemiológicos, envolvendo populações de crianças e adolescentes, uma vez que o IMC constitui alternativa de fácil utilização e não onerosa, quando comparado às demais técnicas para determinação da gordura corporal. 
A formulação de modelos lineares, utilizando valores contínuos de IMC, apresentam a vantagem de evitar a aplicação de pontos de corte para a definição de sobrepeso e obesidade. Os pontos de corte utilizados neste estudo são recomendações da IOTF - International Obesity Task Force - para uso internacional e foram obtidos a partir de dados de diversos países, inclusive o Brasil (COLE e col. 2000). A utilização de análises baseadas nestes pontos de corte tem a vantagem de permitir a comparação entre diferentes estudos.

\subsubsection{BIA e a composição corporal}

A utilização da BIA para a determinação da composição corporal suscita alguns aspectos para discussão. $O$ primeiro diz respeito aos fatores que afetam a quantidade predita das diferentes frações da composição corporal e o segundo, à hidratação da massa magra.

Atividade física, conteúdo da bexiga, ingestão de alimentos e líquidos podem constituir limitações para a realização do exame, principalmente em populações (KUSHNER e col. 1996). No sentido de minimizar a possivel interferência de tais fatores, procurou-se alertar as crianças e adolescentes para realizarem o exame após esvaziamento da bexiga e, além disso, para não fazerem atividade física intensa na manhã do dia do exame.

Com relação à hidratação, convém lembrar que a BIA considera a hidratação da massa magra constante e igual a 73,2\% (FOSTER e LUKASKI 1996, HOUTKOOPER e col. 1996, BRAY e col. 2001, ROGOL e col. 2002). Púberes apresentam variação da hidratação da massa magra, além de rápidas mudanças de massa muscular ocorridas durante a puberdade (BOILEAU e col. 1984, GORAN 1998).

Em indivíduos adultos, muitos estudos validam a técnica de impedância bioelétrica na determinação da composição corporal e diagnóstico de obesidade (HOUTKOOPER e col. 1996, ROUBENOFF 1996). Em adolescentes, a 
maturação sexual e crescimento propiciam alterações constantes na composição corporal, o que influencia o estabelecimento de um padrão de normalidade referente à quantidade de gordura corporal para essa faixa etária. Desta forma, o diagnóstico de sobrepeso e obesidade, nos indivíduos estudados, baseou-se nos valores de IMC e não de gordura corporal.

\subsubsection{As variáveis independentes}

\subsubsection{Consumo alimentar}

A ausência de associação entre o VET da dieta/consumo de lipídios e o IMC/gordura corporal, encontrada nas análises multivariadas, vai ao encontro de diversos estudos realizados com crianças e adolescentes.

MAGAREY e col. (2001) investigaram a relação entre consumo de macronutrientes/NET da dieta e adiposidade (IMC, pregas cutânea triciptal e subescapular) em crianças e adolescentes australianos em seguimento dos 2 aos 15 anos de idade. Nenhum nutriente/NET foi preditor significante da adiposidade em nenhum dos anos/intervalos estudados $(2,4,6,8,11,13$ e 15 anos de idade), após análises transversal e longitudinal, baseada em modelos lineares generalizados.

Estes achados também foram encontrados em estudo realizado com adolescentes italianos que procurou verificar a relação entre IMC e consumo alimentar e atividade física (MAFFEIS e col. 1998).

Estudo realizado com crianças e adolescentes norte-americanos de 9 a 14 anos de idade, participantes do Growing Up Today Study, filhos das participantes do Nurses' Health Study II, foi o único, dentro da revisão bibliográfica realizada, que apresentou relação entre variações anuais de IMC e consumo alimentar. Constataram o VET da dieta como preditor da variação anual de IMC. No entanto, vale ressaltar que todas as variáveis foram obtidas por meio de questionário 
enviado pelo correio, constituindo variáveis referidas e a análise estatística foi a mesma utilizada no presente estudo (BERKEY e col. 2000).

A mensuração do consumo alimentar constitui um dos principais desafios no que diz respeito a investigações nutricionais. Alguns cuidados foram tomados no presente estudo, em relação à coleta e análise dos dados referentes ao consumo alimentar.

A ingestão de lipídios foi ajustada pelo VET da dieta conforme método proposto por WILLET e col. (1997). Este ajuste torna a ingestão do macronutriente independente do valor energético da dieta, uma vez que este representa uma potencial variável de confusão.

Inquéritos alimentares apresentam limitações em relação à capacidade do individuo lembrar a qualidade e quantidade ingerida às refeições. Além da memória, aspectos sobre conhecimento dos alimentos e motivação para responder ao questionário devem ser considerados. Com o intuito de minimizar estes problemas, utilizou-se registro fotográfico e utensílios domésticos para facilitar o inquérito alimentar.

Adicionalmente, sabe-se que no cálculo do peso (gramas) dos alimentos/preparações consumidas e desta quantidade em nutrientes podem ser passíveis de erros devido a imprecisões nas informações fornecidas pelos indivíduos ou pelo aplicativo utilizado. Neste estudo, criou-se planilha de cálculo nutricional com dados nacionais sobre composição de alimentos $e$ as informações nutricionais dos produtos industrializados consumidos, não disponiveis na tabela de composição utilizada, foram pesquisadas nos rótulos e/ou serviços de atendimento ao consumidor.

Cabe lembrar que, em estudos longitudinais, existe a possibilidade de erros, uma vez que a mensuração de uma variável pode influenciar o comportamento futuro 
do individuo em relação aos seus hábitos. Por exemplo, medidas de composição corporal, atividade física e consumo alimentar podem alertar os indivíduos e provocar alteração de seus hábitos alimentares e de atividade física. Desta forma, os dados do consumo alimentar foram coletados somente na terceira coleta.

Durante um período prolongado de tempo, um aumento de $100 \mathrm{kcal} / \mathrm{dia}$ no VET da dieta, além das necessidades energéticas de um indivíduo, resultaria em um ganho substancial de peso. A maior dificuldade em estudos transversais sobre alimentação e adiposidade consiste na mensuração deste efeito cumulativo do excesso do VET da dieta e/ou macronutrientes consumidos na composição corporal. Tal dificuldade constitui possivel explicação para a ausência de relação entre VET da dieta/lipídios e valores transversais de IMC/adiposidade, encontrada no presente estudo.

Em relação às análises longitudinais, é possível que o tempo de seguimento deste estudo tenha sido pequeno para detectar influências do VET/lipidios consumidos nas variáveis variações temporais de IMC e massa adiposa, achado que vai de encontro à hipótese deste estudo.

Recordatórios de 24 horas fornecem retratos pontuais do consumo alimentar de indivíduos. Outros métodos para inquéritos alimentares, como a história alimentar, possivelmente forneceriam informações sobre a ingestão habitual de indivíduos, entretanto, são de difícil aplicação, especialmente entre crianças e adolescentes (GORAN 1998).

\subsubsection{Atividade fisica e sedentarismo}

Esperava-se relação diretamente proporcional entre as variáveis dependentes e sedentarismo e, inversamente proporcional para atividade física. Entretanto, os resultados mostraram que nenhuma das variáveis relacionadas à atividade física 
e/ou sedentarismo constitui fator associado às variáveis dependentes estudadas, achado contrário à hipótese deste estudo.

Além do escore de sedentarismo, foram testadas também, como variáveis independentes, o número de horas despendido assistindo televisão, jogando vídeo game e utilizando o computador, separadamente.

Ausência de relação entre atividade física/sedentarismo e adiposidade também foi encontrada por outros estudos realizados com crianças e adolescentes de países desenvolvidos (BOOT e col. 1997, GORAN e col. 1998, MAGAREY e col. 2001).

BOOT e col. (1997), estudando crianças e adolescentes holandeses entre 4 e 20 anos de idade, encontraram relação entre quantidade absoluta e relativa de gordura corporal (por meio de DEXA) e nível sócio-econômico somente para o sexo feminino. Não foram encontradas associações entre variáveis referentes à atividade física (questionário) e de composição corporal para ambos os sexos, em análise transversal.

Estudo norte-americano, realizado com adolescentes pré-púberes, verificou, em análise baseada em modelo hierárquico, que o gasto energético não constituiu preditor significativo para alteração de gordura corporal (GORAN e col. 1998).

Este achado também foi constatado por MAGAREY e col. (2001) em seguimento com crianças e adolescentes australianos e por MAFFEIS e col. (1998), em coorte com adolescentes italianos.

Estudo realizado com crianças e adolescentes norte-americanos de 9 a 14 anos de idade verificou relação entre variações anuais de IMC e atividade física/sedentarismo. Os autores verificaram que, para ambos os sexos, o sedentarismo na primeira coleta (número de horas/dia assistindo televisão e 
jogando vídeo game) apresentou relação positiva e significativa com a variação anual de IMC. Para o sexo masculino, foi observada, também, relação inversa e significativa para número de horas/dia praticando esportes na primeira coleta e a variação anual de IMC (BERKEY e col. 2000).

Igualmente ao consumo alimentar, a ausência de relação entre atividade física/sedentarismo e IMC/adiposidade observada neste estudo pode ser explicada pela dificuldade na mensuração do efeito a longo prazo da prática de atividades físicas e do sedentarismo. Tal dificuldade pode explicar, também, correlações positivas entre atividade física e IMC/adiposidade para as meninas e correlações negativas entre sedentarismo e IMC/adiposidade para os meninos (Tabela 5). Além de relação proporcional entre atividade física e alteração temporal de IMC/adiposidade e inversamente proporcional entre sedentarismo e variação temporal de IMC para o sexo feminino (Tabela 10).

\subsubsection{Idade e estágio de maturação sexual}

A variável idade foi significativa em todos os modelos lineares que tiveram como variáveis dependentes os valores transversais de IMC e adiposidade (Tabelas 6 e 7), achado que vai ao encontro da hipótese deste estudo. Para a variação temporal de gordura corporal, a idade mostrou-se associada somente para o sexo masculino, enquanto não constituiu variável significante para a variação temporal de IMC, em ambos os sexos (Tabela 11 e 12).

$\mathrm{Na}$ adolescência, a idade cronológica deixa de ser um parâmetro seguro para a caracterização biopsicossocial de um determinado individuo, pois indivíduos de uma mesma idade freqüentemente estão em fases distintas da puberdade devido à variabilidade do início e ritmo do desenvolvimento de cada indivíduo. No entanto, durante a adolescência, as quantidades de gordura corporal e massa magra, bem como as alterações na composição corporal estão associadas a idade cronológica, fato que justifica a relação encontrada nos modelos propostos. Além disso, a idade é variável amplamente utilizada em estudos epidemiológicos 
como variável indicadora do desenvolvimento (DANIELS e col. 1997, MAYNARD e col. 2001).

O EMS não se associou a nenhuma das variáveis dependentes estudadas e o estadiamento do desenvolvimento sexual constitui um dos principais desafios no que diz respeito a estudos com crianças e adolescentes, devido a dificuldade de coleta desta variável.

Neste estudo, descrições detalhadas sobre as diferenças entre os EMS foram utilizadas como intuito de facilitar a auto-avaliação. A literatura não apresenta consenso no que diz respeito à confiabilidade da auto-avaliação para a determinação do EMS de indivíduos, que é verificada, na totalidade dos estudos, pelo coeficiente de concordância entre o estágio da auto-avaliação e o estágio apontado por profissional especializado.

DUKE e col. (1980), avaliando adolescentes norte-americanos de ambos os sexos, encontraram, para as meninas, coeficiente kappa de 0,81 para o desenvolvimento das mamas e 0,91 para pêlos pubianos e para os meninos, coeficiente de 0,88 para um escore combinando o desenvolvimento dos genitais e pêlos pubianos.

Em contrapartida, outro estudo norte-americano, realizado por HERGENROEDER e col. (1999) avaliou a concordância da auto-avaliação em meninas e verificou baixos coeficientes kappa, sendo 0,34 para desenvolvimento das mamas e 0,37 para pêlos pubianos. Os autores comentam os valores de concordância apresentados por outros estudos, que variam de 71 a $93 \%$ para pêlos pubianos (kappa de 0,29 a 0,91) e de 58 a $86 \%$ para desenvolvimento das mamas (kappa de 0,29 a 0,81).

No Brasil, GUIMARÃES e PASSOS (1997) analisaram a concordância entre informações referidas e observadas do EMS de meninas. Os percentuais de 
concordância para desenvolvimento das mamas variaram de 57,3 a $65,2 \%$ e para os pêlos pubianos, entre 65,4 e $73,5 \%$ e foram inferiores aos apresentados na literatura, segundo os autores. Matsudo e Matsudo, citado por SUN e col. (2002), apresentam concordância entre auto-avaliações repetidas variando entre 85 e $95 \%$ em estudos com adolescentes brasileiros.

Alguns estudos avaliaram a possivel interferência de alguns fatores como presença de obesidade, tratamento com hormônios e EMS atual na autoavaliação do estágio de maturação sexual.

FINKELSTEIN e col. (1999) pesquisaram adolescentes de ambos os sexos, com puberdade atrasada (delayed) e que estavam sob tratamento com hormônios. Constataram que não houve efeito do tratamento hormonal e do gênero em relação à concordância entre a avaliação referida e observada, apontando concordância significante entre as duas avaliações.

Estudo examinando a acurácia da auto-avaliação do EMS em adolescentes obesos e eutróficos constatou que as meninas obesas e eutróficas avaliam corretamente seus respectivos EMS para pêlos pubianos. No que se refere ao desenvolvimento das mamas, meninas obesas superestimam seu estágio, enquanto as eutróficas o avaliam corretamente. Uma possivel justificativa para este achado seria a dificuldade de distinguir os casos de lipomastia, possível somente por meio de exame físico realizado por profissional especializado. Meninos, superestimam o desenvolvimento dos pêlos pubianos independente do estado nutricional (BONAT e col. 2002).

Estudo realizado com adolescentes norte-americanos, de ambos os sexos, encontrou diferenças na avaliação quanto às diferentes quantidades de gordura corporal e EMS atual. O coeficiente de correlação de Kendall variou de 0,65 e 0,82 (WILLIAMS e col. 1988) 


\subsubsection{Peso e estatura dos pais}

Estudo com adultos espanhóis apresentou diferenças significativas entre variáveis antropométricas (peso e estatura) referidas e medidas, associadas positivamente com a idade e superiores para o sexo feminino, quando comparadas ao masculino (TORICES e col. 1993). Investigação com adultos neozelandeses apontou diferença significativa entre variáveis medidas e informadas (STEWART e col. 1987), achado encontrado, também, por KUCZMARSKI e col. (2001), estudando a concordância entre peso e estatura referidos e medidos em adultos norte-americanos participantes do Third National Health and Nutrition Examination Survey.

ENGSTROM e col. (2003), em revisão bibliográfica sobre a acurácia de peso e estatura referidos por mulheres adultas, apontam subestimativa do peso corporal em 21 dos 26 artigos revistos e superestimativa da estatura em todos os 36 artigos estudados. No entanto, NAKAMURA e col. (1999) concluíram que o peso e estatura referidos por mulheres japonesas adultas constitui alternativa acurada e precisa, para uso em estudos epidemiológicos.

SPENCER e col. (2002) sugerem a utilização de modelos de correção para peso e estatura referidos, obtidos a partir de uma subamostra, como alternativa para a diminuição do erro na utilização de variáveis referidas, com base em estudo com indivíduos europeus adultos.

No presente estudo, foi realizada mensuração de dados antropométricos das mães com o intuito de corrigir os possiveis erros nos valores do peso e estatura referidos, pois a literatura não apresenta consenso sobre a utilização de variáveis informadas. Cabe lembrar, que, lamentavelmente, ao contrário do peso e estatura materna, as variáveis antropométricas paternas referidas, não puderam ser corrigidas e, por isso, foram excluídas das análises. 
Observou-se, para ambos os sexos, relação positiva entre IMC materno e as variáveis dependentes (Tabelas 6 e 7). O IMC materno não se associou às alterações temporais das variáveis dependentes em estudo (Tabela 11 e 12), enquanto a obesidade materna constituiu fator de risco tanto para sobrepeso quanto obesidade, após ajuste por sexo (Tabela 8 e 9).

Conforme observado em revisão bibliográfica, as variáveis referentes ao estado nutricional dos pais são os principais fatores preditores da obesidade em crianças e adolescentes, achado encontrado também, no presente estudo.

FIGUEROA-COLON e col. (2000) examinaram os preditores das modificações da quantidade absoluta e relativa de gordura corporal (DEXA) em meninas norteamericanas pré-menarca. Após 2,7 anos de seguimento, em média, a porcentagem de gordura dos pais foi a única variável preditora da alteração temporal de quantidade absoluta $\left(R^{2}=0,33\right)$ e relativa $\left(R^{2}=0,22\right)$ de massa adiposa das adolescentes estudadas, após análise de regressão linear multivariada considerando a diferença entre as duas medidas.

Segundo FRISANCHO (2000), em estudo prospectivo com população norteamericana do nascimento aos 15 anos de idade, constatou que o maior preditor dos valores transversais de IMC entre adolescentes, em diferentes idades, foi o IMC dos pais, enquanto peso ao nascer e renda familiar per capita não foram preditores significantes.

MAFFEIS e col. (1998) analisaram adolescentes italianos durante 4 anos visando descrever a relação entre adiposidade (IMC) e variáveis da dieta, atividade física e adiposidade dos pais. Em análise de regressão linear múltipla utilizando dados transversais da primeira coleta realizada, constataram o IMC materno como variável importante na predição do IMC dos adolescentes. Nas análises longitudinais, O IMC materno e paterno foram os preditores da diferença entre os valores de IMC nas duas coletas $\left(R^{2}=0,37\right)$. Já o valor relativo inicial de IMC dos 
adolescentes foi a única variável independente significativa da variação positiva ou negativa do IMC em análise de regressão logística $(O R=1,02)$.

FONSECA e col. (1998) avaliaram os fatores associados ao IMC de adolescentes entre 15 e 17 anos de idade, de Niterói, Rio de Janeiro e constataram que, para meninas, O IMC associou-se positivamente à obesidade familiar, dieta de emagrecimento e omissão do café da manhã. Para os meninos, além destas variáveis citadas, observou-se associação com idade.

Estudos apontam que a relação encontrada entre o estado nutricional dos pais e adiposidade em crianças e adolescentes é permeada por fatores genéticos e ambientais (que incluem hábitos alimentares e de atividade física). MAGNUSSON e RASMUSSEN (2002) encontraram semelhança familiar em relação aos valores de IMC, estudando diversos pares de indivíduos com diferentes graus de parentesco. DAVISON e BIRCH (2002), em estudo com meninas norteamericanas, verificaram que familias propensas à obesidade (definidas em relação aos padrões alimentares e de atividade física) são importantes preditoras para o risco de obesidade entre pré-púberes.

\subsubsection{Peso ao nascer}

No final do século $X X$, esforços se voltaram para o estudo das doenças crônicas não transmissíveis e suas possiveis origens no período fetal e pós-natal. Esta idéia baseia-se na hipótese de que, em resposta à nutrição durante o período fetal, a função e estrutura dos órgãos e/ou tecidos seriam "programados" ou alterados de forma que o indivíduo estivesse predisposto às doenças crônicas na vida futura. Tal predisposição estaria envolvida com o aumento da suscetibilidade aos fatores de risco para patologias como hipertensão arterial, diabetes tipo II e obesidade, como dietas aterogênicas, hipercalóricas e reduzida prática de atividade física (HARDING 2001, ADAIR 2002). 
A mais adequada variável indicadora da nutrição fetal é o peso ao nascer. Estudos mostram que a relação entre esta variável e adiposidade futura tem a forma de um " $U$ ". As elevadas prevalências do baixo peso ao nascer associadas às alterações dos hábitos alimentares e de atividade física ocorridas nas últimas décadas tornam a hipótese de programação fetal tema de grande importância para a saúde pública (LUCAS e col. 1999, ADAIR 2002).

LOOS e col. (2001) sugerem que o baixo peso ao nascer, em indivíduos do sexo masculino, está associado à elevada gordura abdominal e subcutânea na vida adulta, independente de influências maternas e genéticas. Em contraponto, PARSONS e col. (2001), em coorte britânica desde o nascimento até os 33 anos de idade, não encontraram associação entre peso ao nascer e obesidade após ajustes pelo peso materno.

ERIKSSON e col. (2001), em estudo longitudinal finlandês, constataram que a obesidade na vida adulta associa-se ao peso ao nascer, IMC aos 7 anos de idade e IMC materno, para ambos os sexos. No entanto, para meninos, tanto baixo $(O R=2,04)$ quanto elevado $(O R=1,86)$ peso ao nascer representaram fatores de risco para o desenvolvimento da obesidade, enquanto para meninas, somente o baixo peso constituiu fator de risco $(O R=1,69)$.

Para a população adolescente, estudo realizado em Israel constatou risco de obesidade aos 17 anos de idade aumentado para aqueles com peso ao nascer elevado, enquanto os adolescentes com baixo peso ao nascer não apresentaram diferenças em relação ao grupo de referência, nascidos com peso entre 2500 e 3500 gramas (SEIDMAN e col. 1991).

Por fim, FRISANCHO (2000) constatou que crianças com elevado peso ao nascer tornam-se adolescentes obesos somente quando os pais também são obesos. Em análise de regressão linear, utilizando como variáveis independentes o peso 
ao nascer, IMC da mãe, IMC do pai e renda per capita, somente as variáveis dos pais associaram-se aos valores de IMC.

No presente estudo, observou-se relação significativa entre peso ao nascer e valores transversais de IMC e quantidade absoluta de gordura corporal, somente entre as meninas estudadas (Tabela 6), juntamente com o IMC materno e renda per capita, achados diferentes dos encontrados por FRISANCHO (2000). Para o sexo masculino, nenhuma relação foi observada entre o peso ao nascer e as variáveis dependentes (Tabela 7).

O peso ao nascer superior ou igual a $3500 \mathrm{~g}$ constituiu fator de risco (OR: 1,71/ IC: 1,06 - 2,75) para o desenvolvimento de sobrepeso nas crianças e adolescentes estudados (Tabela 8), enquanto não foi observada relação entre sobrepeso e baixo peso ao nascer, achados similares aos encontrados por SEIDMAN e col. (1991).

O peso ao nascer referido pelos pais foi utilizado para as análises do presente estudo. WALTON e col. (2000) e O'SULLIVAN e col. (2000) apontam elevada concordância entre o peso ao nascer referido pelos pais e arquivos médicos do sistema de saúde em estudos relativos a adolescentes irlandeses e ingleses. Entretanto, não foram encontrados estudos sobre a acurácia do peso ao nascer referido pelos pais em países em desenvolvimento.

\subsubsection{Renda per capita}

A variável renda per capita, utilizada como indicadora do nivel sócio-econômico, mostrou relação positiva com as variáveis dependentes, para ambos os sexos (Tabela 6 e 7). Ao analisar as variações do IMC e gordura corporal, a renda per capita associou-se positivamente somente para a quantidade relativa e absoluta de gordura corporal entre os meninos (Tabela 12). Tal achado confirma a hipótese do presente estudo. 
Uma revisão dos estudos envolvendo nível sócio-econômico e obesidade aponta que, em paises em desenvolvimento a maior freqüência de obesidade aparece nos estratos de maior renda elou escolaridade, indo ao encontro dos achados do presente estudo (WHO 2000). Ressalta-se que a variável renda per capita apresentou maior significância estatística nos modelos propostos, quando comparada à escolaridade materna.

Entretanto, estudo sobre prevalência de sobrepeso e obesidade em adolescentes brasileiros, realizado por MAGALHÃES e MENDONÇA (2003), mostra que, entre as meninas da região Sudeste, a menor prevalência foi encontrada no estrato mais alto de renda. Esta tendência de inversão da relação entre NSE e obesidade no país, foi reportada também entre mulheres adultas (MONTEIRO e col. 2003).

Possivelmente, 0 acesso a informações, que incluem apelos dos meios de comunicação sobre a importância da prevenção da obesidade e patologias associadas, contribuiria para que mulheres com NSE mais elevado apresentassem maior preocupação com a saúde e estilos de vida mais saudáveis. Entre adolescentes, a preocupação com aspectos estéticos e imagem corporal constituiria fator adicional para cuidados com a saúde, peso corporal e hábitos saudáveis (MAGALHÃES e MENDONÇA 2003, MONTEIRO e col. 2003).

Entre adolescentes do sexo feminino, preocupações com estética, imagem corporal e informações sobre as potenciais conseqüências do sobrepeso/obesidade à saúde explicariam, também, menor prevalência de obesidade observada entre meninas, quando comparados aos meninos (Tabela 1). Prevalência superior para o sexo masculino, quando comparado ao feminino também foi encontrada por MAGALHÃES e MENDONÇA (2003), em adolescentes de 15 a 19 anos de idade, da região Sudeste do Brasil. 


\subsubsection{Valor inicial da variável dependente}

Para a construção dos modelos das variações temporais de IMC e gordura corporal, realizaram-se análises utilizando como variáveis independentes os valores da primeira coleta, da terceira coleta, a diferença entre a terceira e primeira e a média entre as duas coletas, conforme realizado por BERKEY e col. (2000). Optou-se pela utilização dos valores da primeira coleta, pois foram as variáveis de maior significância nas análises realizadas.

O valor inicial da variável dependente associou-se às alterações temporais em todos os modelos propostos e esta variável constituiu, também, variável de controle.

Estudos longitudinais sobre as alterações de IMC e gordura corporal em crianças e adolescentes apresentam o valor inicial com importante variável associada (HEDIGER e col. 1995, BERKEY e col. 2000, MAGAREY e col. 2001).

HEDIGER e col. (1995) estudaram alterações anuais (medida final - medida inicial) no peso e pregas cutâneas de adolescentes norte-americanas, de 14 a 18 anos de idade, após a menarca. Para a variação anual da prega cutânea tricipital (PCT), os principais preditores foram idade, PCT inicial e variação de IMC $\left(R^{2}=\right.$ $0,33)$. Para a variação anual da prega cutânea subscapular - PCS, as variáveis foram idade, número de cigarros/dia, PCS inicial e variação de $I M C\left(R^{2}=0,28\right)$. Este estudo, aponta, ainda, velocidade positiva de aumento para PCS e negativa para PCT evidenciando processo de depósito centralizado de gordura corporal em adolescentes pós-menarca.

MAGAREY e col. (2001) constataram que o valor prévio de IMC associou-se, significantemente, às alterações temporais de IMC. O índice de massa corporal materno também foi significativo na análise da variação temporal entre 13 e 15 anos de idade $\left(R^{2}=0,76\right)$. Os valores prévios das pregas cutâneas foram as únicas variáveis preditoras significativas para variação de prega tricipital e 
subescapular, para todas as outras faixas etárias estudadas, inclusive a de 13 a 15 anos de idade.

Estudo norte-americano constatou que, além da adiposidade dos pais, sexo e quantidade inicial de gordura corporal também foram variáveis importantes na predição da alteração de massa adiposa (GORAN e col. 1998).

É possivel que o tempo de seguimento deste estudo tenha sido pequeno para detectar maiores influências das variáveis estudadas nas variações temporais de IMC e massa adiposa. Além disso, outros fatores não estudados possivelmente explicariam parte da variabilidade dos valores e alterações encontrados neste estudo. Entre eles, encontram-se os fatores hormonais responsáveis pelas mudanças na composição corporal durante a adolescência, como as gonadotrofinas, leptina, esteróides e hormônio do crescimento (ROGOL e col. 2000).

\subsection{Validade externa}

A discussão da validade externa de um estudo diz respeito à possibilidade de generalização dos resultados obtidos.

Em revisão bibliográfica, não foram encontradas investigações com delineamento longitudinal referentes às alterações temporais das variáveis antropométricas entre adolescentes brasileiros. A literatura apresenta algumas publicações representativas da população infanto-juvenil do país, baseadas em análises de tendência de sobrepeso e obesidade (magnitude e distribuição) observadas em estudos populacionais com delineamento transversal, como a Pesquisa Nacional de Saúde e Nutrição - PNSN (WANG e col. 2002, MAGALHÃES e MENDONÇA 2003).

WANG e col. (2002) apresentaram prevalências de sobrepeso e obesidade para crianças e adolescentes brasileiros baseados nos dados da Pesquisa Nacional de Saúde e Nutrição dos anos de 1996-1997. O diagnóstico foi baseado nos 
mesmos pontos de corte utilizados no presente estudo. Constataram prevalência de sobrepeso de $12,6 \%$ para adolescentes, de ambos os sexos, na faixa etária entre 10 e 18 anos de idade. No presente estudo, a prevalência de sobrepeso foi de $27,9 \%$, sendo 2,2 vezes maior que a encontrada para a população brasileira.

MAGALHÃES e MENDONÇA (2003) encontraram prevalência de sobrepeso/obesidade de $11,5 \%$ para a região Sudeste do país, sendo 8,5 e $14,6 \%$ para meninas e meninos entre 15 e 19 anos de idade, respectivamente. Vale ressaltar que o ponto de corte utilizado foi o recomendado pela Organização Mundial de Saúde baseados nos valores da população norte-americana. No presente estudo, para a mesma faixa etária, a prevalência de sobrepeso/obesidade foi superior ao encontrado para a região Sudeste, para ambos os sexos (14,3\% para o sexo feminino e $30,8 \%$ para o sexo masculino).

A comparação dos dados da literatura com os encontrados neste estudo é dificultada pelas diferenças de delineamento e critérios utilizados para o diagnóstico de sobrepeso/obesidade, bem como diferentes populações de referência e pontos de corte, dificultando a generalização dos resultados obtidos.

\subsection{Recomendaçōes}

Embora não tenha sido observada relação entre $\mathrm{IMC/adiposidade} \mathrm{e} \mathrm{atividade}$ física/sedentarismo e consumo alimentar enfatiza-se a necessidade de incentivo à prática de exercícios físicos regulares, bem como hábitos alimentares saudáveis para a população estudada.

Acredita-se que, informações sobre estilos de vida saudáveis sejam fundamentais para a prevenção de sobrepeso/obesidade e, a escola seria um veículo eficiente para educação e informação, não só entre as crianças e adolescentes como também para seus pais e familiares. 
Crianças e adolescentes filhos de mães obesas constituem grupo alvo para programas públicos de saúde voltados para a prevenção de sobrepeso/obesidade.

Recomendam-se estudos voltados para a relação entre peso ao nascer e adiposidade futura, uma vez que esta variável pode representar fator de risco para o desenvolvimento de sobrepeso/obesidade. 
CONCLUSÃO 


\section{CONCLUSÃO}

Os fatores associados ao sobrepeso e obesidade das crianças e adolescentes estudados foram diferentes para meninas e meninos.

O IMC materno, renda per capita e idade associaram-se positivamente aos valores transversais de IMC e gordura corporal, em ambos os sexos.

Peso ao nascer constituiu fator associado positivamente ao IMC e adiposidade somente entre as meninas e peso ao nascer acima de $3500 \mathrm{~g}$ constituiu fator de risco para sobrepeso.

Obesidade materna foi importante preditora para a presença de sobrepeso e obesidade, ajustada por sexo. Indivíduos filhos de mães obesas têm chance aproximadamente duas vezes maior de apresentarem sobrepeso quando comparados aos filhos de mães eutróficas. Crianças e adolescentes, filhos de mães obesas apresentaram chance 4,2 vezes maior de obesidade em relação aos filhos de mães eutróficas.

Entre as meninas, o valor inicial (da primeira coleta), constituiu único fator associado à variação temporal de IMC e massa adiposa. Entre os meninos, o valor do índice de massa corporal na primeira coleta e renda per capita associaram-se à variação temporal de IMC, enquanto os valores iniciais, idade e renda per capita associaram-se a quantidade de gordura corporal em $\mathrm{kg} \mathrm{e} \%$.

Nas análises multivariadas, as variáveis estágio de maturação sexual, valor energético total da dieta, consumo de lipídios, atividade física, sedentarismo e escolaridade materna não se associaram ao sobrepeso e obesidade no grupo estudado. 
REFERÊNCIAS 


\section{REFERÊNCIAS}

Adair LS. Early nutrition conditions and later risk of disease. In: Caballero B, Popkin BM. The nutrition transition: diet and disease in the developing world. London, Academy Press, 2002. p.129-45.

Ball EJ, O'Connor J, Abbott R, Steinbeck KS, Davies PSW, Wishart C, Gaskin KJ, Baur LA. Total energy expenditure, body fatness, and physical activity in children aged 6-9y. Am J Clin Nutr 2001;74:524-8.

Barker M, Robinson S, Osmond C, Barker DJP. Birth weight and body fat distribution in adolescent girls. Arch Dis Child 1997; 77:381-3.

Berkey CS, Rockett HRH, Field AE, Gillman MW, Frazier L, Camargo CA, Colditz GA. Activity, dietary intake, and weight changes in a longitudinal study of preadolescent and adolescent boys and girls. Pediatrics 2000 [on line] Disponivel em <URL:http://unw. pediatrics.org/cgi/content/full/105/4/e56

Boileau RA, Lohman TG, Slaughter MH, Ball TE, Going SB, Hendrix MK. Hydration of the fat-free body in children during maturation. Hum Biol 1984; 56 : 651-66.

Bonat S, Pathomvanich A, Keil MF, Field AE, Yanovski JA. Self-assessment of pubertal stage in overweight children. Pediatrics 2002;110:743-7.

Boot AM, Bouquet J, Ridder J, Krenning EP, Muinck Keizer-Schrama S. Determinants of body composition measures by dual-energy $\mathrm{X}$-ray absorptiometry in Dutch children and adolescents. Am J Clin Nutr 1997; 66:232-8.

Bray GA, DeLany JP, Harsha DW, Volaufova J, Champagne CC. Evaluation of body fat in fatter and leaner 10-y-old African American and white children: the Baton Rouge Children's Study. Am J Clin Nutr 2001; 73: 687-702. 
Cavadini C, Decarli B, Dirren H, Cauderay M, Narring F, Michaud PA. Assessment of adolescent food habits in Switzerland. Appetite 1999; 32: 97-106.

Cole TJ, Bellizi MC, Flegal KM, Dietz WH. Establishing a standard definition for child overweight and obesity worldwide: international survey. BMJ 2000; 320:1240-3.

Colli AS, Coates V, Guimarães EMB. Monitoração do crescimento e desenvolvimento físico. In: Coates V. Medicina do adolescente. São Paulo: Sarvier; 1993. p. 51-65.

Cooper C, Kun D, Egger P, Wadsworth M, Barker D. Childhood growth and age at menarche. Br J Obstet Gynaecol 1996; 103: 814-7.

Daniels SR, Khoury PR, Morrison JÁ. The utility of body mass index as a measure of body fatness in children and adolescents: differences by race and gender. Pediatrics 1997; 99: 804-7.

Davison KK e Birch LL. Childhood overweight: a contextual model and recommendations for future research. Obes Rev 2001; 2: 159-71.

Davison KK e Birch LL. Obesigenic families: parents' physical activity and dietary intake patterns predict girls' risk of overweight. Int J Obes 2002; 26: 1186-93.

Dietz WH e Gortmaker SL. Do we fatten our children at the television set? Obesity and television viewing in children and adolescents. Pediatrics 1985; 75: 807-12.

Dietz WH. Critical periods in childhood for the development of obesity. Am J Clin Nutr 1994; 59: 955-9. 
Dietz WH. Periods of risk in childhood for the development of adult obesity-what do we need to learn? J Nutr 1997; 127(9): 1884-86.

Duke PM, Litt IF, Gross RT. Adolescents' self-assessment of sexual maturation. Pediatrics 1980; 66(6): 918-920.

Ebbeling CB, Pawlak DB, Ludwig DS. Childhood obesity: public-health crisis, common sense cure. Lancet 2002;360:473-82.

Ellis KJ, Abrams SA, Wong WW. Monitoring childhood obesity: assessment of the weight/height ${ }^{2}$ index. Am J Epidemiol 1999; 150: 939-46.

Engstrom JL, Paterson SA, Doherty A, Trabulsi M, Speer KL. Accuracy of selfreported height and weight in women: an integrative review of the literature. $J$ Midwifery Womens Health 2003; 48: 338-45.

Eriksson J, Forsén T, Tuomilehto J, Osmond C, Barker D. Size at birth, childhood growth and obesity in adult life. Int J Obes 2001; 25: 735-40.

Figueroa-Colon R, Arani RB, Goran MI, Weinsier RL. Paternal body fat is a longitudinal predictor of changes in body fat in premenarcheal girls. Am J Clin Nutr 2000; 71:829-34.

Filozof C, Gonzalez C, Sereday M, Mazza C, Braguinsky J. Obesity prevalence and trends in Latinamerican countries. Obes Rev 2001; 2:99-106.

Finkelstein JW, D'Arcangelo MR, Susman EJ, Chinchilli VM, Kunselman SJ, Schwab J, Demers LM, Liben LS, Kulin HE. Self-assessment of physical sexual maturation in boys and girls with delayed puberty. J Adolesc Health 1999; 25:379-81. 
Flegal KM, Carroll MD, Ogden CL, Johnson CL. Prevalence and trends in obesity among US. adults, 1999-2000. JAMA 2002; 288(4):1723-7.

Fonseca VM, Sichieri R, Veiga GV. Fatores associados à obesidade em adolescentes. Rev Saude Publica 1998; 32: 541-9.

Foster KR e Lukaski HC. Whole-body impedance - what does it measure? Am J Clin Nutr 1996; 64 (suppl): 388S-96S.

Frisancho AR. Prenatal compared with parental origins of adolescent fatness. Am J Clin Nutr 2000;72:1186-90.

Frisch RE. The right weight: body fat, menarche and fertility. Proc Nutr Soc 1994; 53: 113-29.

Frutuoso MFP, Bismarck-Nasr EM, Gambardella AMD. Redução do dispêndio energético e excesso de peso corporal em adolescentes. Rev Nutr 2003; 16 : $257-63$.

Fung TT, Rimm EB, Spiegelman D, Rifai N, Tofler GH, Willet WC, Hu FB. Association between dietary patterns and plasma biomarkers of obesity and cardiovascular disease risk. Am J Clin Nutr 2001; 73:61-7.

Gambardella AMD, Frutuoso MFP, Ferreira CF. Prática alimentar de adolescentes. Rev Nutr 1999; 12: 55-63.

Garn SM, LaVelle M, Rosenberg KR, Hawthorne VM. Maturational timing as a factor in female fatness and obesity. Am J Clin Nutr 1986; 43: 879-83. 
Goran MI, Schewchuk R, Gower BA, Nagy TR, Carpenter WH, Johnson RK. Longitudinal changes in fatness in white children: no effect of childhood energy expenditure. Am J Clin Nutr 1998; 67:309-16.

Goran MI. Measurement issues related to studies of childhood obesity: assessment of body composition, body fat distribution, physical activity, and food intake. Pediatrics 1998;101:505-18.

Gordon CC, Chumlea WC, Roche AF. Stature, recumbent lenght, and weight. In: Lohman TG, Roche AF, Martorell R. Anthropometric standardization reference manual. Champaign: Human Kinetics Books; 1988. p. 3-8.

Grund $A$, Krause $H$, Siewers $M$, Rieckert $H$, Müller MJ. Is TV viewing an index of physical activity and fitness in overweight and normal weight children?. Public Health Nutr $2001 ; 4(6): 1245-51$.

Guimarães JP e Passos ADC. Análise da concordância entre informações referidas e observadas acerca do estadiamento pubertário entre escolares do sexo feminino. Rev Saude Publ 1997; 31(3): 263-71

Hair J, Anderson RE, Tatham RL, Black WC. Multivariate data analysis. $5^{\mathrm{a}}$ ed., London, Prentice Hall, 1998.

Harding JE. The nutrition basis of the fetal origins of adult disease. Int $\mathbf{J}$ Epidemiol 2001; 30: 15-23.

Hardman AE. Physical activity and health: current issues and research needs. Int J Epidemiol 2001; 30:1193-7.

Hediger ML, Scholl TO, Schall JI, Cronk CE. One-year changes in weight and fatness in girls during late adolescence. Pediatrics 1995; 96:253-8. 
Hergenroeder AC, Hill RB, Wong WW, Sangi-Haghpeykar H, Taylor W. Validity of self-assessment of pubertal maturation in African American and European American adolescents. J Adolesc Health 1999; 24: 201-5.

Houtkooper LB, Lohman TG, Going SB, Howell WH. Why bioelectrical impedance analysis should be used for estimating adiposity. Am J Clin Nutr 1996; 64(suppl): 436S-48S.

[IBGE] Fundação Instituto Brasileiro de Geografia e Estatística. Estudo Nacional de Despesa Familiar. Tabela de composição de alimentos. Rio de Janeiro, IBGE; 1996; 137p.

Jakicic JM. The role of physical activity in prevention and treatment of body weight gain in adults. $\mathbf{J}$ Nutr 2002; 132:3826S-9S.

Jung RT. Obesity as a disease. Br Med Bull 1997; 53(2): 307-21.

Kaplowitz PB, Slora EJ, Wasserman RC, Pedlow SE, Herman-Giddens ME. Earlier onset of puberty in girls: relation to increased body mass index and race. Pediatrics 2001;108:347-53.

Kuczmarski MF, Kuczmarski RJ, Najjar M. Effects of age on validity of selfreported height, weight, and body mass index: findings from the Third National Health and Nutrition Examination Survey, 1988-1994. J Am Diet Assoc 2001; 101: $28-34$.

Kushner RF, Gudivaka R, Schoeller DA. Clinical characteristics influencing bioelectrical impedance analysis measurements. Am J Clin Nutr 1996; 64(suppl): 423S-7S 
Loos RJF, Beunen G, Fagard R, Derom C, Vlietinck R. Birth weight and body composition in young adult men - a prospective twin study. Int J Obes 2001; 25: $1537-45$.

Lucas A, Fewtrell MS, Cole TJ. Fetal origins of adult disease - the hypothesis revisited. BMJ 1999; 319: 245-9.

Lukaski HC. Methods for the assessment of human body composition: traditional and new. Am J Clin Nutr 1987; 46: 537-56.

Maffeis C, Talamini G, Tatò L. Influence of diet, physical activity and parents' obesity on children's adiposity: a four-year longitudinal study. Int J Obes 1998, 22: $758-64$.

Magalhães VC e Mendonça GAS. Prevalência e fatores associados a sobrepeso e obesidade em adolescentes de 15 a 19 anos das regiões Nordeste e Sudeste do Brasil, 1996 a 1997. Cad Saúde Publica 2003; 19(Sup1): S129-S139.

Magarey AM, Daniles LA, Boulton TJC, Cockington RA.. Does fat intake predict adiposity in healthy children and adolescents aged 2-15y? A longitudinal analysis. Eur J Clin Nutr 2001, 55: 471-81.

Magnusson PKE e Rasmussen F. Familial resemblance of body mass index and familial risk of high and low body mass index. A study of young men in Sweden. Int J Obes 2002; 26: 1225-31.

Maynard LM, Wisemandle W, Roche AF, Chumlea WC, Guo SS, Siervogel RM. Childhood body composition in relation to body mass index. Pediatrics 2001; 107: $344-50$ 
Mei Z, Grummer-Strawn LM, Pietrobelli A, Goulding A, Goran MI, Dietz WH. Validity of body mass index compared with other body-composition screening indexes for the assessment of body fatness in children and adolescents. Am J Clin Nutr 2002; 75: 978-85.

Monteiro CA, Conde WL, Popkin BM. Is obesity replacing or adding to undernutrition? Evidence from different social classes in Brazil. Public Health Nutr 2002; 5: 105-12.

Monteiro CA, Conde WL, de Castro IRR. A tendência cambiante da relação entre escolaridade e risco de obesidade no Brasil (1975-1997). Cad Saúde Publica 2003; 19(Sup1): S67-S75.

Nakamura K, Hoshiro Y, Kodama K, Yamamoto M. Reliability of self-reported body height and weight of adult Japanese women. J Biosoc Sci 1999; 31: 555-8.

Ogden CL, Flegal KM, Carroll MD, Johnson CL. Prevalence and trends in overweight among US. children and adolescents, 1999-2000. JAMA 2002; 288(4):1728-32.

Okasha M, McCarron P, McEwen J, Smith GD. Age at menarche: secular trends and association with adult anthropometric measures. Ann Hum Biol 2001; 28: 6878.

O'Sullivan JJ, Pearce MS, Parker L. Parental recall of birth weight: how accurate is it? Arch Dis Child 2000; 82: 202-3.

Parsons TJ, Power C, Manor O. Fetal and early life growth and body mass index from birth to early adulthood in 1958 British cohort: longitudinal study. BMJ 2001; 323: $1331-5$ 
Popkin BM. The dynamics of the dietary transition in the developing world. In: Caballero B, Popkin BM. The nutrition transition: diet and disease in the developing world. London, Academy Press, 2002. p.111-28.

Prentice AM e Jebb SA. Obesity in Britain: gluttony or sloth? BMJ 1995; 311:4379.

Reilly JJ, Methven E, McDowell ZC, Hacking B, Alexander D, Stewart L, Kelnar CJH. Health consequences of obesity. Arch Dis Child 2003; 88:748-52.

RJL Systems. Bioelectrical Impedance Analysis [on line]. Disponivel em $<U R L: h t t p: / / u w w . r j l s y s t e m s . c o m / r e s e a r c h . h t m l$. [27 out 2000]

Rogol AD, Clark PA, Roemmich JN. Growth and pubertal development in children and adolescents: effects of diet and physical activity. Am J Clin Nutr 2000; 72 (suppl):521S-8S.

Rogol AD, Roemmich JN, Clark PA. Growth at puberty. J Adolesc Health 2002; 31: $192-200$.

Rosenbaum M e Leibel RL. The physiology of body weight regulation: relevance to the etiology of obesity in children Pediatrics 1998; 101: 525-39

Roubenoff R. Applications of bioelectrical impedance analysis for body composition to epidemiologic studies. Am J Clin Nutr 1996; 64(Suppl):459-62.

Seidman DS, Laor A, Gale R, Stevenson DK, Danon YL. A longitudinal study of birth weight and being overweight in late adolescence. AJDC 1991; 145: 782-5.

Spencer EA, Appleby PN, Davey GK, Key TJ. Validity of self-reported height and weight in 4808 EPIC- Oxford participants. Public Health Nutr 2002; 5: 561-5. 
Statacorp. Stata Statistical Software: Release 6.0. College Station, TX: Stata Corporation, 1999.

Steinbeck KS. The importance of physical activity in the prevention of overweight and obesity in childhood: a review and an opinion Obes Rev 2001, 2:117-30.

Stewart AW, Jackson RT, Ford MA, Beaglehole R. Underestimation of relative weight by use of self-reported height and weight. Am J Epidemiol 1987; 125: 122-6.

Sun SS, Schubert CM, Chumlea WC, Roche AF, Kulin HE, Lee PA, Himes JH, Ryan AS. National estimates of the timing of sexual maturation and racial differences among US children. Pediatrics 2002; 110: 911-9.

Torices JCA, Nadal JF, Guisasola FA, Mejia RH, Espinar AC. Self-reported height and weight and prevalence of obesity: study in a Spanish population. Int $\mathbf{J}$ Obes Relat Metab Disord 1993; 17: 663-7

Van Lenthe FJ, Kemper HCG, Van Mechelen W. Rapid maturation in adolescence results in greater obesity in adulthood: The Amsterdam Growth and Health Study. Am J Clin Nutr 1996; 64: 18-24.

Walton KA, Murray LJ, Gallagher AM, Cran GW, Savage MJ, Boreham C. Parental recall of birthweight: a good proxy for recorded birthweight. Eur $\mathbf{J}$ Epidemiol 2000; 16: 793-6.

Wang Y, Ge K, Popkin BM. Tracking of body mass index from childhood to adolescence: a 6-y follow-up study in China. Am J Clin Nutr 2000, 72:1018-24. 
Wang Y. Cross-national comparison of childhood obesity: the epidemic and the relationship between obesity and socioeconomic status. Int J Epidemiol 2001;30:1129-36.

Wang $Y$. Is obesity associated with early sexual maturation? A comparison of the association in American boys versus girls. Pediatrics 2002; 110:903-10.

Wang Y, Monteiro CA, Popkin BM. Trends of obesity and underweight in older children and adolescents in the United States, Brazil, China and Russia. Am J Clin Nutr 2002; 75:971-7.

[WHO] World Health Organization. Physical status: the use and interpretation of anthropometry. Geneva, 1995. (Technical Report Series, 854)

[WHO] World Health Organization. Obesity: preventing and managing the global epidemic. Geneva, 2000 (Technical Report Series, 894)

Willet WC, Howe GR, Kushi LH. Adjustment for total energy intake in epidemiologic studies. Am J Clin Nutr 1997; 65(suppl): 1220S-8S

Williams RL, Cheyne KL, Houtkooper LK, Lohman TG. Adolescent selfassessment of sexual maturation - effects of fatness classification and actual sexual maturation stage. J Adolesc Health Care 1988; 9: 480-2.

Zabotto CB, Vianna RPT, Gil MF. Registro fotográfico para inquéritos dietéticos - utensilios e porções. NEPA-UNICAMP/DNUT-UFG. Goiânia, 1996. 
ANEXOS 
ANEXO 1

FORMULÁRIO

Pesquisa: Antropometria e composição corporal de crianças e adolescentes

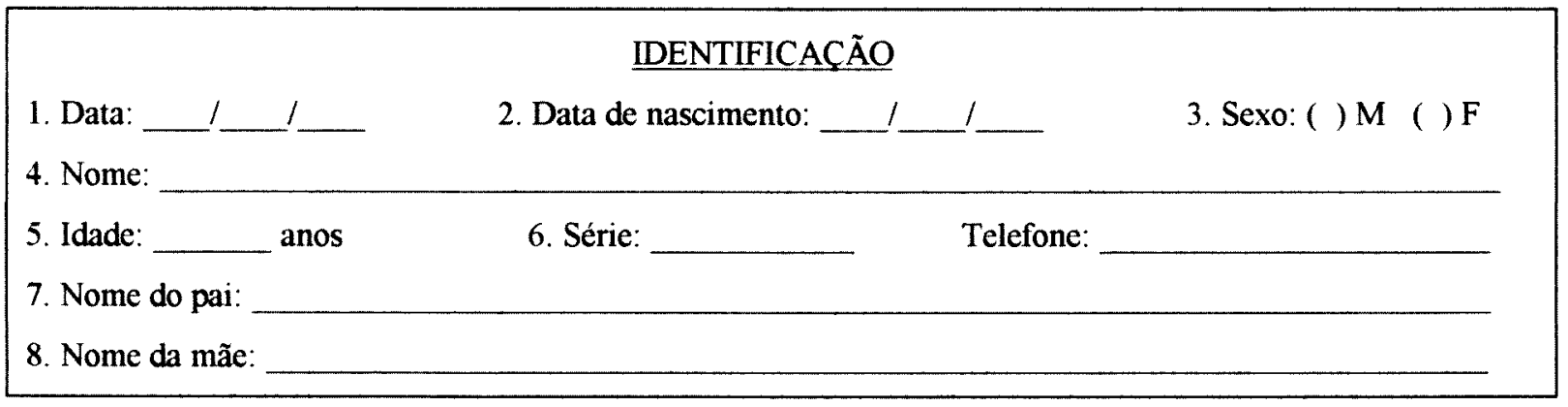

\section{ATIVIDADE FÍSICA}

9. Você assiste à televisão? ( ) Sim ( ) Não

10. Quantas horas/dia?

11. Quantos dias/semana?

12. Você joga vídeo game? ( ) Sim ( ) Não

13. Quantas horas/dia?

14. Quantos dias/semana?

15. Você utiliza o computador? ( ) Sim ( ) Não

16. Quantas horas/dia?

17. Quantos dias/semana?

18. O que você faz. nos fins de semana?

19. A que horas você dorme?

20. A que horas você acorda?

21. Você pratica algum esporte (incluindo as aulas de Educação Física) ? ( ) Sim ( ) Não

22. Qual (is)?

23. Quantas horas/dia?

24. Quantas dias/semana?

25. Você tem algum irmão ou irmã que estuda neste colégio? ( ) Sim ( ) Não

Qual é o nome e em que série ele (a) estuda?

DADOS ANTROPOMÉTRICOS E IMPEDÂNCIA BIOELÉTRICA

\begin{tabular}{|c|c|c|}
\hline Medida & Estatura & $\begin{array}{c}\text { Altura } \\
\text { sentada }\end{array}$ \\
\hline 1 & & \\
\hline 2 & & \\
\hline 3 & & \\
\hline
\end{tabular}

26. Peso:

27. Reactância:

28. Resistência: 


\section{ANEXO 2 \\ QUESTIONÁRIO}

Este questionário faz parte da pesquisa "Antropometria e composição corporal de crianças e adolescentes" e é de grande importância a obtenção das informações abaixo. Peço a colaboração dos senhores pais e/ou responsáveis no preenchimento das questões e que, por favor, envie-as pelos seus (suas) filhos (as). Atenciosamente, Maria Fernanda.

\section{Identificação:}

1. Nome do filho (a):

2. Qual a data de nascimento do seu filho:

3. Endereço completo:

4. Nome do pai:

5. Nome da mãe:

Dados sobre a saúde de Sr (Sra) e de seu (sua) filho (a):

6. Com quantos quilos seu (sua) filho (a) nasceu?

7. O seu filho foi amamentado ao peito? ( ) sim ( ) não

8. Em caso afirmativo, por quantos meses?

9. Qual o peso da mãe? 10. E a altura?

11 Qual o peso do pai? 12. E a altura?

\section{Nível sócio-econômico:}

13. Quantas pessoas vivem em sua casa?

14. Qual a escolaridade materna? (informe até qual série a senhora estudou)

15. Qual a escolaridade paterna?

16. Qual a ocupação materna?

17. Qual a ocupação paterna?

18. Somando o salário de todas as pessoas que trabalham em sua casa, qual a renda familiar total mensal? 
№ Ques.

\section{ANEXO 3}

FORMULÁRIO DE ESTADIAMENTO SEXUAL

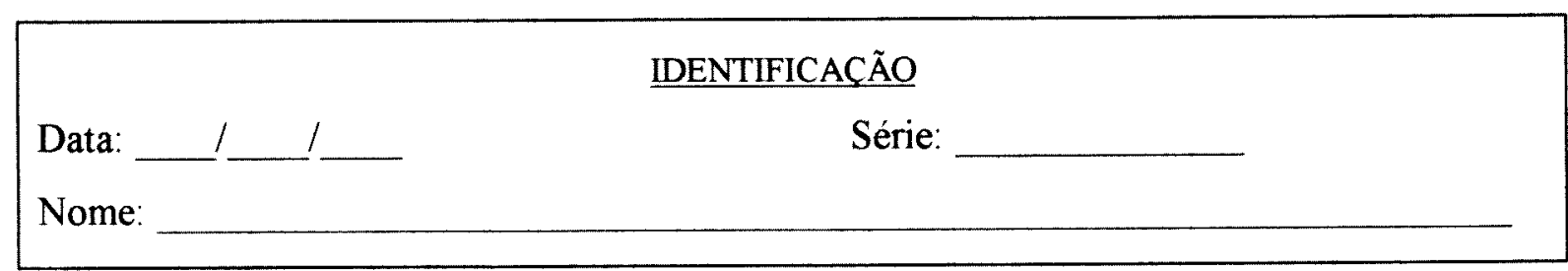

MATURAÇÃO SEXUAL - MENINOS

29. Desenvolvimento dos pêlos pubianos

\begin{tabular}{|l|l|l|l|l|} 
P1 & P2 & P3 & P4 & P5 \\
\hline
\end{tabular}

30. Desenvolvimento dos genitais

\begin{tabular}{|l|l|l|l|l|}
\hline G1 & G2 & G3 & G4 & G5 \\
\hline
\end{tabular}

№ Ques.

\section{IDENTIFICACÃO}

Data: Série:

Nome:

\section{MATURACÃ̃O SEXUAL - MENINAS}

31. Você já teve a primeira menstruação? ( ) Sim ( ) Não

32. Se sim, com que idade? anos

33. Desenvolvimento dos pêlos pubianos

\begin{tabular}{|l|l|l|l|l|}
\hline P1 & P2 & P3 & P4 & P5 \\
\hline
\end{tabular}

34. Desenvolvimento das mamas

\begin{tabular}{|l|l|l|l|l|}
\hline M1 & M2 & M3 & M4 & M5 \\
\hline
\end{tabular}




\section{ANEXO 4}

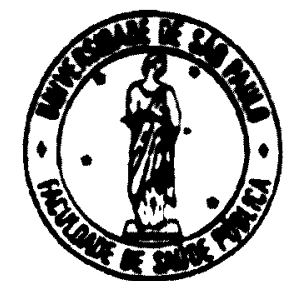

\section{UNIVERSIDADE DE SÃO PAULO FACULDADE DE SAÚDE PÜBLICA COMITÉ DE ÉTICA EM PESQUISA-COEP \\ At. Dr. Arnaldo, 715 - Cerqueira César \\ São Paulo-SP - CEP: 01246-904 \\ Telefone: (0xx11) 3066-7779 - e-mail: mdgracas $a$ usp.br}

\section{Of.COEP/034/01}

21 de março de 2001

Pelo presente, informo que o Comitê de Ética em Pesquisa da Faculdade de Saúde Pública da Universidade de São Paulo-COEP, analisou e aprovou, em sua 2. ${ }^{a} / 00$ Sessão Ordinária, de 20.03 .01 , de acordo com os requisitos da Resolução CNS/196/96, o Protocolo de Pesquisa n. 427, intitulado: "CRESCIMENTO E COMPOSIÇÃO CORPORAL DE ADOLESCENTES", apresentado pela pesquisadora Maria Fernanda Petroli Frutuoso.

Atenciosamente,

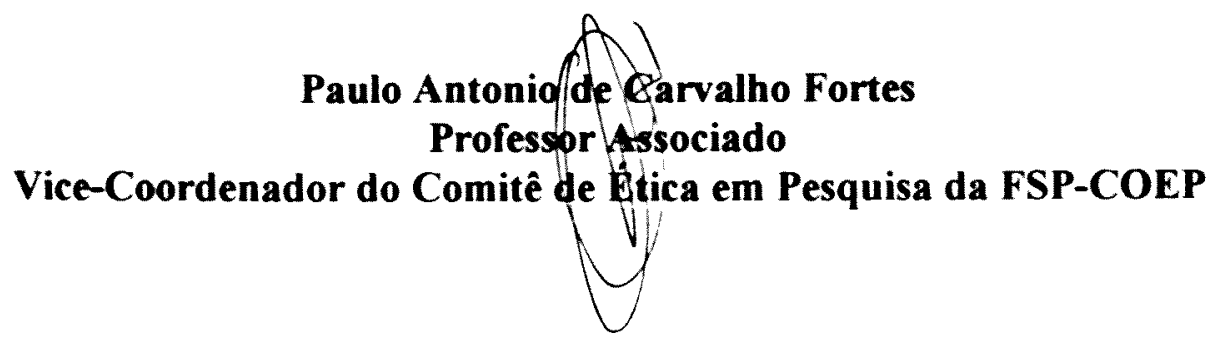




\section{ANEXO 5 \\ UNIVERSIDADE DE SÃO PAULO \\ FACULDADE DE SAÚDE PÚBLICA \\ DEPARTAMENTO DE NUTRIÇÃO}

São Paulo, de de 2001 .

Ao Sr. (a)

Coordenador da Instituição

Após contato prévio, formalizamos pedido de autorização para realização da pesquisa: "Antropometria e alterações na composição corporal de crianças e adolescentes", sob nossa responsabilidade.

Será realizada pesquisa com os alunos matriculados nessa instituição, com o objetivo de analisar o crescimento e composição corporal de crianças e adolescentes. Todos os alunos estarão cientes dos objetivos e metodologia do estudo e seus pais firmarão concordância com a participação na pesquisa.

Enviamos cópia do projeto com detalhamento das atividades a serem realizadas e nos colocamos à disposição para eventuais dúvidas e sugestões pelo endereço e telefone:

Departamento de Nutrição - Faculdade de Saúde Pública - Universidade de São Paulo

Prof $^{2}$ Dr $^{\mathrm{a}}$ Ana Maria Dianezi Gambardella ou Maria Fernanda Petroli Frutuoso

Av. Dr Arnaldo, 715 - CEP 01246-904 -São Paulo

Fone: $3066-7705$

Agradeço, novamente, a colaboração

Maria Fernanda Petroli Frutuoso 


\section{ANEXO 6 \\ UNIVERSIDADE DE SÃO PAULO \\ FACULDADE DE SAÚDE PÚBLICA \\ DEPARTAMENTO DE NUTRIÇÃO}

São Paulo, agosto de 2001.

Pesquisa: Antropometria e composição corporal de crianças e adolescentes.

Departamento de Nutrição - Faculdade de Saúde Pública - Universidade de São Paulo.

Prezados pais e/ou responsáveis

Após o consentimento dos responsáveis pelo Colégio, será realizada pesquisa com seus (suas) filhos (as), matriculados nesta instituição.

Esse trabalho tem como objetivo analisar o crescimento e alterações na composição corporal de crianças e adolescentes. Para tanto, é importante que o senhor (a) leia com atenção e responda o questionário em anexo e envie-o pelo seu (sua) filho (a).

O exame de impedância bioelétrica consiste em teste para a mensuração da composição corporal. Os indivíduos serão deitados em superficie plana e serão colocados eletrodos no pé e mão direitos, que emitirão corrente elétrica imperceptivel. O exame não causa danos à saúde e é indolor. A avaliação do estágio de maturação sexual será realizada por meio de auto-avaliação. As crianças e adolescentes escolherão, individualmente, a foto que mais se assemelha ao seu estágio de desenvolvimento atual (dentre 5 fotos do desenvolvimento da genitália e pêlos pubianos para os meninos e desenvolvimento das mamas e pêlos pubianos para as meninas).

Caso o senhor (a) não saiba ou não tenha certeza de seu peso e altura, peço a gentileza de procurar uma farmácia próxima para que este dado seja preenchido.

Qualquer dúvida sobre a pesquisa poderá ser respondida durante o trabalho, no colégio de seu (sua) filho (a) ou através dos telefones: (011) 9600-8853/283-2945. Agradeço antecipadamente a colaboração e me coloco à disposição para qualquer esclarecimento.

Maria Fernanda Petroli Frutuoso 
PESQUISA: “Antropometria e composição corporal de crianças e adolescentes”

(de acordo com a resolução 196 de 10/10/1996 do Conselho Nacional de Saúde)

$\mathrm{Eu}$,

livremente, concordo em participar e autorizo meu (minha) filho(a),

participar da pesquisa "Antropometria e composição corporal de crianças e adolescentes" sob a responsabilidade da pesquisadora Maria Fernanda Petroli Frutuoso, doutoranda da Faculdade de Saúde Pública da Universidade de São Paulo e orientação da Prof ${ }^{\mathrm{a}}$ Dr $^{\mathbf{r}^{\mathrm{a}}}$ Ana Maria Dianezi Gambardella da mesma instituição.

Objetivo da pesquisa: verificar o crescimento e alterações na composição corporal de crianças e adolescentes.

Participação: responder a um questionário e permitir que sejam realizadas medidas de peso, estatura, impedância bioelétrica, altura sentada e avaliação do estágio de maturação sexual de seu(sua) filho(a). Serão realizadas 3 medidas, com intervalo de seis meses entre elas.

Riscos: Não haverá riscos para a integridade física, mental ou moral do $\operatorname{Sr}(a)$ e seu(sua) filho(a).

Beneficios: As informações obtidas nesta pesquisa poderão ser úteis cientificamente e, também trarão informações sobre a saúde do $\operatorname{Sr}(a)$ e seu(sua) filho(a).

Privacidade: Os dados individualizados serão confidenciais. Os resultados coletivos serão divulgados nos meios científicos.

Contato com os pesquisadores: Terei acesso ao telefone para esclarecimento de dúvidas e reclamações.

Desistência: Poderei desistir a qualquer momento da minha participação e de meu (minha) filho(a), sem qualquer conseqüência para mim e para ele(a).

São Paulo, de de 2001, 